\title{
Phoenix - A Model-Based Human Reliability Analysis Methodology: Qualitative Analysis Procedure
}

\author{
Nsimah J. Ekanem*a, ${ }^{\text {a,1 }}$ Ali Mosleh ${ }^{\mathrm{a}, 2}$ and Song-Hua Shen ${ }^{\mathrm{b}}$ \\ ${ }^{a}$ Center for Risk and Reliability, University of Maryland, College Park, USA \\ ${ }^{\mathrm{b}}$ US Nuclear Regulatory Commission, Washington, DC, USA
}

\begin{abstract}
Phoenix method is an attempt to address various issues in the field of human reliability analysis (HRA). Built on a cognitive human response model, Phoenix incorporates strong elements of current HRA good practices, leverages lessons learned from empirical studies, and takes advantage of the best features of existing and emerging HRA methods. Its original framework was introduced in previous publications. This paper reports on the completed methodology, summarizing the steps and techniques of its qualitative analysis phase. The methodology introduces the "crew response tree" which provides a structure for capturing the context associated with human failure events (HFEs), including errors of omission and commission. It also uses a team-centered version of the Information, Decision and Action cognitive model and "macro cognitive" abstractions of crew behavior, as well as relevant findings from cognitive psychology literature and operating experience, to identify potential causes of failures and influencing factors during procedure-driven and knowledge-supported crewplant interactions. The result is the set of identified HFEs and likely scenarios leading to each. The methodology itself is generic in the sense that it is compatible with various quantification methods, and can be adapted for use across different environments including nuclear, oil and gas, aerospace, aviation, and healthcare.
\end{abstract}

Keywords: Probabilistic Risk Assessment (PRA), Human Reliability Analysis (HRA), Human Failure Event (HFE), Performance Influencing Factor (PIF), Crew Failure Mode (CFM), Crew Response Tree (CRT)

\section{INTRODUCTION}

Phoenix, as the name implies is developed from the ashes of its predecessors in an attempt to address the current issues in the field of Human Reliability Analysis (HRA). Presently, dozens of HRA methods exist and new methods are still being developed. In the nuclear industry, the need for improved HRA methodologies for application to Probabilistic Risk Assessment (PRAs) has motivated a number of major activities in research and development worldwide since early 1990s. These efforts have resulted in some improvements in the application of the so-called first generation HRA methods (e.g. Technique for Human Error Rate Prediction -THERP [1], Human Error Assessment and Reduction Technique - HEART [2], Success Likelihood Index Method Multiattribute Utility Decomposition - SLIM-MAUD [3]) and a number of new techniques and frameworks often referred to as second generation, or advanced methods (e.g. Cognitive Reliability and Error Analysis Method CREAM [4], Standardized Plant Analysis Risk Human Reliability Analysis - SPAR-H [5], Information, Decision and Action in Crew context - IDAC [6]) that have been developed.

Major limitations of the first generation methods in error identification and error probability quantification have been widely discussed and can be summarized as follows:

- The methods lacked procedures for identifying perhaps the most risk-significant category of human error, errors of commission (EOC), as compared with errors of omission (EOO).

- For the errors covered, the methods do not provide a convincing basis for error probabilities, and no theoretical foundations were offered for the quantification procedures. The limited

\footnotetext{
*11 Corresponding author: Chevron Technology Company, Houston, TX, USA; email: njekanem@gmail.com

${ }^{2}$ Current affiliation: University of California, Los Angeles, CA, USA
} 
experimental data used by some methodologies were insufficient to instill confidence in numbers on statistical grounds.

- Methods do not provide a causal picture of operator error - a need if one wishes to take steps towards reducing error probabilities. The basic assumption of the quantification methods in virtually all first generation methods is that error probabilities can be estimated using some explicit or implicit function relating a set of "Performance Shaping Factors" (PSFs) to error probabilities.

- Methods were insufficiently structured to prevent significant analyst-to-analyst variability of the results generated.

The development of the second generation HRA methods has taken place mostly along two parallel tracks. One track attempts to enhance the quality of HRA analysis within the "classical" framework of PRA [7], [8]. The other track reflects the belief that substantive improvement in HRA for PRA applications requires structural changes to the PRA methodology, moving from the static, hardwaredriven view of the world to a more flexible dynamic model of accident scenarios. One way of achieving this is by integrating models of operator behavior, plant thermal-hydraulic response, and systems performance in a probabilistic-deterministic simulation approach [6]. These two tracks also share many common objectives and face many similar challenges. Both intend to address error identification and probability estimation which are the two key components of a comprehensive HRA methodology. These methods have an increased emphasis on context and operator cognition than firstgeneration methods. However, they still have some limitations which include:

- The lack of sufficient theoretical and experimental basis for the key ingredients and fundamental assumptions of many of these methods.

- The lack of a causal model of the underlying causal mechanisms to link operator response to measurable Performance Influencing Factors (PIFs) / PSFs or other characterization of the context.

- Majority of the proposed approaches still rely on very simple and in some cases implicit functions to relate PIFs to probabilities without the theoretical or empirical basis for such relations.

- In many instances, numbers are the result of expert elicitation, use of highly subjective scales, and unsubstantiated "reference probabilities".

In general, these issues in both first and second generation HRA methods have led to inconsistencies, insufficient traceability and reproducibility in both the qualitative and quantitative phases. Also, it has resulted in significant variability in the results seen in the application of different HRA methods, and also in cases where different HRA analysts apply the same method.

The framework for this model-based hybrid HRA methodology was originally proposed in [9], [10] in an attempt to address the aforementioned issues. It incorporates strong elements of current HRA good practices, leverages lessons learned from empirical studies and takes advantage of the best features of existing and emerging HRA methods. The methodology itself is generic in the sense that it is compatible with a number of popular HRA quantification methods, and can be adapted for use across various environments including nuclear, oil and gas, aerospace, aviation, and healthcare. The specific version presented in this paper is developed for use in nuclear power plant PRA to support HRA in full-power internal events PRAs, low-power and shutdown operations, event assessment, and significance determination. Extensions to fire and seismic PRAs can be easily developed on the same foundations. Essentially what changes from one application domain to another are specific details of the analysis modules, techniques of the approach, and emphasis placed on aspects that are more relevant to the particular application.

The development of this methodology has been completed and this paper provides a summary of the steps and techniques of the qualitative analysis phase. It discusses the major steps and important substeps required by an HRA analyst to successfully implement this methodology. Also presented are the products of each step and the information required by the analyst in order to conduct the analysis. The detailed quantitative analysis aspect of Phoenix HRA is covered in [11], with an overview provided in [12]. 


\section{THE QUALITATIVE ANALYSIS FRAMEWORK}

The broad objective of HRA qualitative analysis is to identify Human Failure Events (HFEs) and characterize crew-system scenarios that lead to those HFEs. As such, there is a tight coupling between understanding and analyzing the plant/system response and conditions (systems behavior), and understanding and analyzing the crew activities (operator behavior). Therefore, the process of HFE identification and the definition of the scenarios leading to the HFEs are, in general, inseparable from the process of modeling the plant response in a Probabilistic Risk Assessment (PRA).

The qualitative analysis framework uses two modeling vehicles namely [10]: (1) A process and representational method for analyzing crew-plant interactions with a focus on the identification and quantification of HFEs and possible recoveries, and (2) A human response model which relates the observable Crew Failures Modes (CFM) to "context factors" for example, Performance Influencing Factors (PIFs). These are explained in more details in the following sections.

\subsection{Layers of the Framework}

The framework has three main layers namely: the Crew Response Tree (CRT) (top layer), the human performance model (mid layer) and the PIFs (bottom layer). The framework layers and its relationship to a typical PRA Event Tree (or Event Sequence Diagram) model are shown in Figure 2-1.

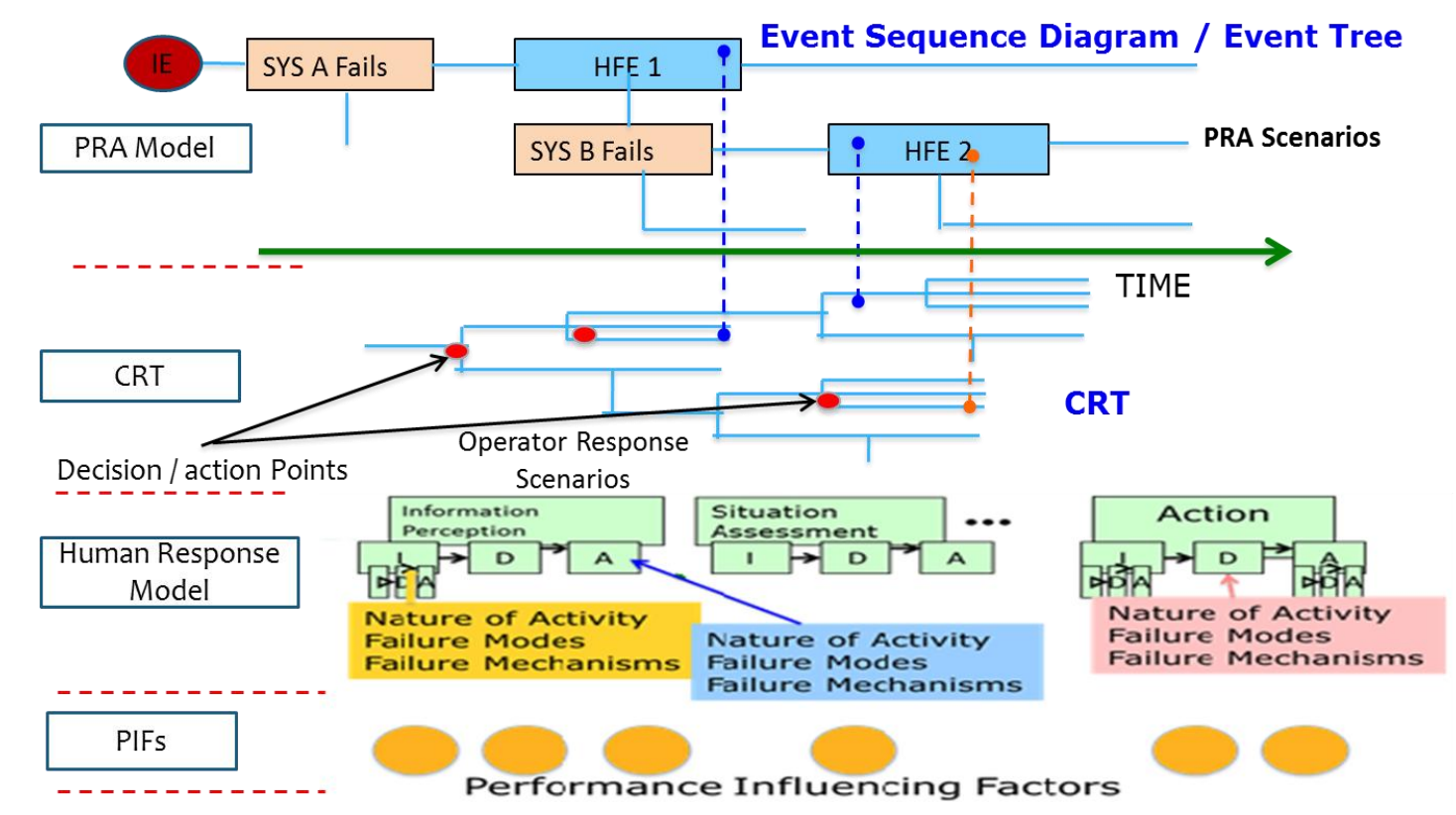

Figure 2-1: The Phoenix qualitative analysis framework layers and a typical PRA event sequence model

The CRT provides a structure for capturing the context associated with the HFE, including errors of omission and commission. A team-centered version of the Information, Decision and Action (IDA) cognitive model [13] is used to represent the human response model, while the PIFs represent the set of context factors (including plant factors) that affect human performance.

\section{OVERVIEW OF THE HRA QUALITATIVE ANALYSIS PROCESS}

The HRA qualitative analysis process broadly involves the identification of Human Failure Events (HFEs) and the characterization of crew-plant scenarios that lead to the HFEs. Generally, it is assumed that the starting point for the qualitative analysis is the identification and definition of the HFEs. This process can be generally defined as a four-step process [11], [14] namely: identification and definition of the HFE and its Probabilistic Risk Assessment (PRA) scenarios context; task analysis; identification 
of failure causes; and the assessment of influence of context. The above steps, captured through appropriate tools and techniques, are reflected in the following process flow diagram (Figure 3-1). The diagram recognizes two distinct possibilities as the starting point of the analysis: (1) HFEs are identified as part of an existing PRA model, or (2) HFEs are to be identified in an iterative process as part of the analysis.

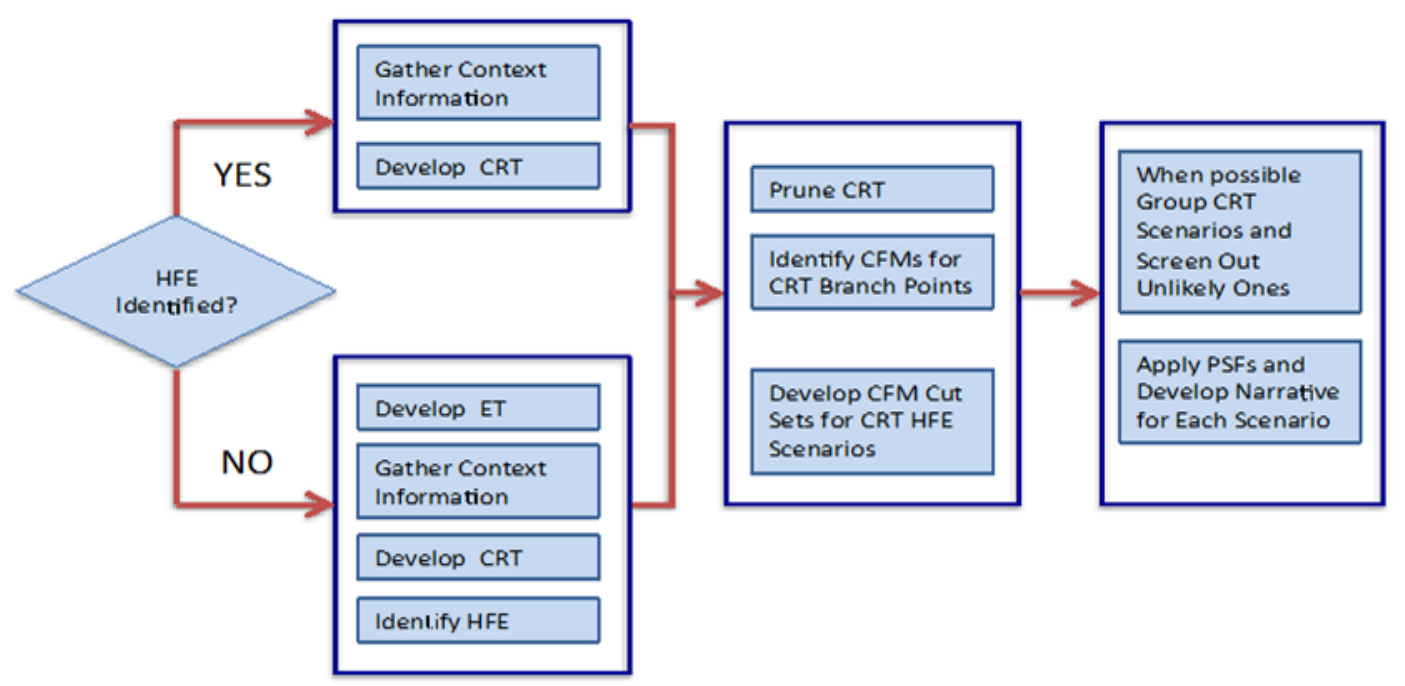

Figure 3-1: Overview of the Phoenix Qualitative Analysis Process

\section{THE QUALITATIVE ANALYSIS PROCEDURE GUIDE}

The main steps, important sub-steps and the products of each step are summarized in Table 4-1 [11] and discussed in more detail in the following sections.

\subsection{Step 1: PRA Scenario Development/Familiarization}

In general, the objectives of steps 1 and 2 (in part) are to identify and incorporate Human Failure Events (HFEs) (which, in a PRA context, are defined as functional failures, such as failure to initiate feed and bleed before core damage occurs) into a Probabilistic Risk Assessment (PRA). If the PRA models, i.e, Event Sequence Diagram (ESD), Event Trees (ET) and corresponding Fault Trees (FTs), exist and HFEs are identified, step 1 of the qualitative analysis primarily becomes the process of analysts gaining familiarity with the PRA scenarios leading to the HFEs and gathering the needed information to support construction of the Crew Response Tree (CRT) and completion of other qualitative analysis steps. Otherwise, the analysis starts with the development of the PRA models and, ideally, concurrent and iterative development of CRTs. When starting with an existing HFE, the process may indeed lead to the modifications of the HFE or the addition of new ones to the PRA. The following describe the sub-steps of Step 1:

\section{Step 1.A: Use standard PRA steps to Build/Review ET or ESD}

This step follows standard PRA practice for PRA scenario modeling.

\section{Step 1.B: Select PRA Scenario and Collect Context Information}

The analysts need to become familiar with the PRA scenario related to the HFE(s). This includes plant visits and other activities to gather information on what, how, and why the scenario might evolve as described. The information collected would be useful during the development of the CRT(s). Additional related information will need to be collected as identified failure paths are evaluated for potential recovery branches during the $\mathrm{CRT}(\mathrm{s})$ development. The information needed include: description of the PRA scenario; expected cues (available plant information); applicable procedural guidance; required actions (manipulations) for success; and timing. 
Table 4-1: Steps and Products of the Qualitative Analysis Procedure

\begin{tabular}{|c|c|c|}
\hline Steps & Sub-Steps & Product \\
\hline $\begin{array}{l}\text { 1. Develop/Identify PRA } \\
\text { scenarios for analysis }\end{array}$ & $\begin{array}{l}\text { - Use standard PRA steps to } \\
\text { build or review ET or ESD for } \\
\text { the IE } \\
\text { - Select PRA scenario and } \\
\text { gather general context } \\
\text { information for scenario }\end{array}$ & $\begin{array}{l}\text { - ESD/ET } \\
\text { - Plant Scenario Context } \\
\text { Factors } \\
\text { - Major safety functions in } \\
\text { ESD/ET }\end{array}$ \\
\hline 2. Develop CRT & $\begin{array}{l}\text { - Perform Task Analysis } \\
\text { (procedure review) } \\
\text { - Construct CRT } \\
\text { - Prune/Simplify CRT } \\
\text { - Add HFEs to PRA model if } \\
\text { necessary }\end{array}$ & $\begin{array}{l}\text { - CRT } \\
\text { - HFEs } \\
\text { - Possibly modified PRA } \\
\text { model }\end{array}$ \\
\hline $\begin{array}{l}\text { 3. Identify Crew Failure } \\
\text { Modes for CRT Branches }\end{array}$ & $\begin{array}{l}\text { - Trace CFM Causal Models } \\
\text { (FTs) for various CRT } \\
\text { branches on scenarios leading } \\
\text { to HFEs and keep portions } \\
\text { applicable to each branch }\end{array}$ & $\begin{array}{l}\text { - CFM sub-trees for CRT } \\
\text { branches }\end{array}$ \\
\hline $\begin{array}{l}\text { 4. Develop CRT } \\
\text { scenarios for HFE (s) in } \\
\text { terms of CFMs and } \\
\text { relevant context factors } \\
\text { and PIFs }\end{array}$ & $\begin{array}{l}\text { - Link FTs of CRT scenarios to } \\
\text { HFEs of interest and solve } \\
\text { linked model } \\
\text { - Identify relevant PIFs for CRT } \\
\text { scenario using the CFM - PIF } \\
\text { BBN model }\end{array}$ & $\begin{array}{l}\text { - CRT scenario CFM "cut } \\
\text { sets" } \\
\text { - List of PIFs for each }\end{array}$ \\
\hline $\begin{array}{l}\text { 5. Analyze Scenarios, } \\
\text { Write Narrative, Trace } \\
\text { Dependencies }\end{array}$ & $\begin{array}{l}\text { Describe scenarios as } \\
\text { sequences of crew cognitive } \\
\text { and physical activities and } \\
\text { factors contributing to the } \\
\text { success of single or multiple } \\
\text { failures (HFEs) }\end{array}$ & $\begin{array}{l}\text { - Narratives for HFE } \\
\text { scenarios } \\
\text { - Qualitative Insights } \\
\text { - Input to Quantification }\end{array}$ \\
\hline
\end{tabular}

\subsection{Step 2: Development of Crew Response Tree (CRT)}

The CRT is a visual representation of the crew-plant interaction scenarios leading to HFEs as well as a structure that supports the performance and documentation of the qualitative analysis. The CRT can be devoted to find paths to predefined HFEs and possible recoveries, or used as a vehicle to also identify new HFEs. CRTs can be constructed for crew response situations that are Procedure Driven (PD), Knowledge Driven (KD), or a Hybrid of both (HD) [15]. The CRT leads analysts to perform a thorough assessment of the conditions that could lead crews to take inappropriate paths. This will obviously lead to a more extensive qualitative analysis and a broader consideration of the conditions that could lead crews to fail, along with different ways in which they could fail. The structure facilitates systematic identification of variations in conditions that could lead the crew to take inappropriate paths. The following describe the sub-steps of Step 2:

\section{Step 2.A: Perform Task Analysis and review relevant procedures}

Task analysis is aimed at identifying subtasks associated with the operator actions related to the specific HFE of interest. One of the main issues in task analysis is determining where to stop task parsing, i.e. determining when to stop decomposing the task into sub-tasks in order to obtain the right level of detail required for the analysis. This is necessary to promote consistency and traceability among different analyst using this methodology and also to prevent the analysis being done at 
different levels of abstraction. Hence, guidelines for task analysis is provided to aid in identifying the sub-tasks (at the appropriate level of detail) associated with the crew's actions and cognitive processes related to the specific HFE of interest.

A task can be described by starting from the overall system functional goal(s), and then breaking it down to the level of individual operations. In order to successfully perform this decomposition, the analyst needs to consider the functional, cognitive, and procedural requirements of the task to be analyzed. Among other features, the CRT is a tool for task decomposition of the particular safety function of interest. The functional requirements are covered in the CRT flowchart construction process by decomposing the safety function into individual crew member actions. In addition to the CRT, the human response model (Information, Decision and Action model - IDA) is also used as a vehicle for task decomposition. Within each of the IDA elements, a nested I-D-A structure may exist. The level of decomposition of these IDA elements depends on the amount of detail needed for the task analysis and parsing of different human activities into "sub-events" or sub-tasks. In addition to the nested IDA structure, the human response model has both cognitive and physical requirements embedded in it. Connected together, both modeling tools (the CRT and associated IDA fault trees) in conjunction with the PRA model provide the flow of task analysis. Collectively, they provide the analyst with the information on what to consider in the task analysis. This mixture of procedures, cognitive and physical processes, and system functions and interfaces aid in the task breakdown of the crew's response to an identified safety function.

In the task analysis process, each task can be decomposed into different task steps and these task steps can be characterized in terms of the activities that are involved. We have provided a set of activities to serve as a guide to the entire process. These activities represent the types of activities generally carried out by the crew. When combined with the IDA model, each crew activity can be associated with the different IDA phases (Table 4-2). We assume that in their interactions with the plant, the crew carries out four main functions; (1) Noticing/ detecting / understanding, (2) Situation assessment / Diagnosis, (3) Decision-making / Response planning, and (4) Action taking. These functions correspond to the different IDA phases. Each crew activity can be described in terms of any of the combinations of the four functions it requires (see Table 4-2).

There are no hard and fast rules on where to stop task parsing. However, we are providing some guidelines on which the analyst could base his or her decision. The level of task decomposition required for task analysis can be based on: (a) the level of detail required in the PRA model, (b) the resources available for modeling and conducting the analysis, (c) the HRA requirements and purpose of the analysis, (d) the amount and type of information available, and (e) the success criteria for achieving the safety function. In summary, the analyst should take the following steps to conduct task analysis: identify the HFE of interest; identify the overall task; decompose the overall task into subtasks and each subtask into other subtask depending on the level of detail required in the analysis with the aid of the aforementioned guidelines; use the types of crew activities to characterize each subtask in the lowest level of the task decomposition.

Table 4-2 is used to relate the subtask characterized with the types of crew activities involved with the four main cognitive and physical functions, IDA phases and Crew Failure Modes (CFMs). Therefore, each sub-task can also be traced back to the corresponding phase(s) of the IDA human response model. 
Table 4-2: Relationship between types of Crew Activities, CFMs and IDA phases [11]

\begin{tabular}{|c|c|c|c|c|c|c|c|c|c|c|c|c|c|c|c|c|c|c|c|}
\hline \multirow{4}{*}{$\begin{array}{c}\text { Types of } \\
\text { crew } \\
\text { activities }\end{array}$} & \multicolumn{19}{|c|}{ Human Response Model (IDA) } \\
\hline & \multicolumn{9}{|c|}{ Information Processing (I) } & \multicolumn{7}{|c|}{$\begin{array}{l}\text { Diagnosis/Decision making } \\
\text { (D) }\end{array}$} & \multicolumn{3}{|c|}{$\begin{array}{c}\text { Action } \\
\text { Taking (A) }\end{array}$} \\
\hline & \multicolumn{9}{|c|}{$\begin{array}{l}\text { Noticing/ Detecting / } \\
\text { Understanding }\end{array}$} & \multicolumn{3}{|c|}{$\begin{array}{c}\text { Situation } \\
\text { assessment } \\
\text { / } \\
\text { Diagnosis }\end{array}$} & \multicolumn{4}{|c|}{$\begin{array}{c}\text { Decision } \\
\text { making / } \\
\text { Response } \\
\text { planning }\end{array}$} & \multicolumn{3}{|c|}{$\begin{array}{l}\text { Action } \\
\text { taking }\end{array}$} \\
\hline & $\begin{array}{l}1 \\
1\end{array}$ & 1 & $\begin{array}{l}1 \\
3\end{array}$ & $\begin{array}{l}1 \\
4\end{array}$ & $\begin{array}{l}1 \\
5\end{array}$ & $\begin{array}{l}1 \\
6\end{array}$ & $\begin{array}{l}1 \\
7\end{array}$ & $\begin{array}{l}1 \\
8\end{array}$ & $\begin{array}{l}1 \\
9\end{array}$ & $\begin{array}{l}\mathrm{D} \\
1\end{array}$ & $\begin{array}{l}\mathbf{D} \\
2\end{array}$ & $\begin{array}{l}\mathbf{D} \\
3\end{array}$ & $\begin{array}{l}D \\
4 \\
\end{array}$ & \begin{tabular}{|l|}
$D$ \\
5 \\
\end{tabular} & $\begin{array}{l}D \\
6\end{array}$ & $\begin{array}{l}\text { D } \\
7\end{array}$ & $\begin{array}{l}\text { A } \\
1\end{array}$ & $\begin{array}{l}\text { A } \\
2\end{array}$ & $\begin{array}{l}\text { A } \\
3\end{array}$ \\
\hline \multicolumn{20}{|l|}{ Monitor } \\
\hline \multicolumn{20}{|l|}{ Scan } \\
\hline \multicolumn{20}{|l|}{$\begin{array}{l}\text { Detect / } \\
\text { Observe }\end{array}$} \\
\hline \multicolumn{20}{|l|}{ Identify } \\
\hline \multicolumn{20}{|l|}{ Communicate } \\
\hline \multicolumn{20}{|l|}{$\begin{array}{l}\text { Evaluate / } \\
\text { Interpret }\end{array}$} \\
\hline \multicolumn{20}{|l|}{ Record } \\
\hline \multicolumn{20}{|l|}{ Compare } \\
\hline \multicolumn{20}{|l|}{ Verify } \\
\hline \multicolumn{20}{|l|}{ Adapt } \\
\hline \multicolumn{20}{|l|}{ Adhere } \\
\hline \multicolumn{20}{|l|}{ Diagnosis } \\
\hline \multicolumn{20}{|l|}{ Decide } \\
\hline \multicolumn{20}{|l|}{ Plan } \\
\hline Coordinate & & & & & & & & & & & & & & & & & & & \\
\hline Execute & & & & & & & & & & & & & & & & & & & \\
\hline Regulate & & & & & & & & & & & & & & & & & & & \\
\hline Maintain & & & & & & & & & & & & & & & & & & & \\
\hline $\begin{array}{l}\text { I1: Key Alarm r } \\
\text { unintentional) }\end{array}$ & & & & to 1 & & & & & & D1 & Pla & t/Sy & stem & Stat & e M & sdia & snose & & \\
\hline 12: Data Not O & ine & $(\ln$ & ent & on & & & & & & $\mathrm{D} 2$ & Pro & edu & re M & lisint & erpr & ted & & & \\
\hline 13: Data Discou & & & & & & & & & & & atio & ure t & $\mathrm{Ad}$ & apt $\mathrm{P}$ & & dur & to tl & & \\
\hline 14: Decision to & op & ath & ring & $\mathrm{Da}$ & & & & & & D4 & Pro & edu & re St & ep 0 & mitt & d (I & tent & ona & \\
\hline 15: Data Incorr & ly & oce & ssec & & & & & & & D5 & Del & iatio & fro & $\mathrm{mPr}$ & oce & ure & & & \\
\hline 16: Reading Err & & & & & & & & & & D6 & Dec & ision & to $D$ & Delay & Acti & & & & \\
\hline 17: Informatior & lisc & $\mathrm{mm}$ & unic & ate & & & & & & D7 & Ina & pro & oriat & e Str & teg & $\mathrm{Ch}$ & sen & & \\
\hline 18: Wrong Dat & our & e At & tenc & ed & & & & & & $\mathrm{A} 1$ & Inc & rrec & Tim & ing $\mathrm{c}$ & $f A c$ & ion & & & \\
\hline 19: Data Not Cl & 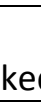 & wit & $A p$ & oro & riat & $\mathrm{Fre}$ & que & ncy & & $\begin{array}{l}\mathrm{A} 2 \\
\mathrm{Col}\end{array}$ & $\operatorname{lng}$ & $\begin{array}{ll}\text { rrec } \\
\text { lent }\end{array}$ & $\begin{array}{l}\text { Ope } \\
\text { Obje }\end{array}$ & $\begin{array}{l}\text { erati } \\
\text { ect }\end{array}$ & & & & & \\
\hline & & & & & & & & & & $\mathrm{A} 3$ & Act & on o & $\mathrm{Wr}$ & rong & Com & & nt / & & \\
\hline
\end{tabular}




\section{Step 2.B: Construct CRT}

In order to simplify the process of constructing the CRT, a modular approach is proposed. CRTs are developed to model HFEs corresponding to a given safety function. Safety function may refer to the intended function of a specific plant system, a desired state of the plant or system in response to plant upset, or a combination of both. Sometimes, there is more than one safety function along the path to the HFE. Under the modular approach, one CRT will be developed for each of the identified safety function. These function-based CRTs may be linked through simple merge rules, thereby producing larger and more comprehensive CRTs to cover the full range of an accident timeline and possible scenarios as reflected in the corresponding PRA Event Tree (ET) or Event Sequence Diagram (ESD) [15].

The construction of the CRT can benefit from a flowchart to enhance consistency and completeness. The CRT Flowchart Figure 4-1 is to be viewed as the procedure aiding the analyst in the CRT development process. The questions in the flowchart guide the addition of branches to the CRT.

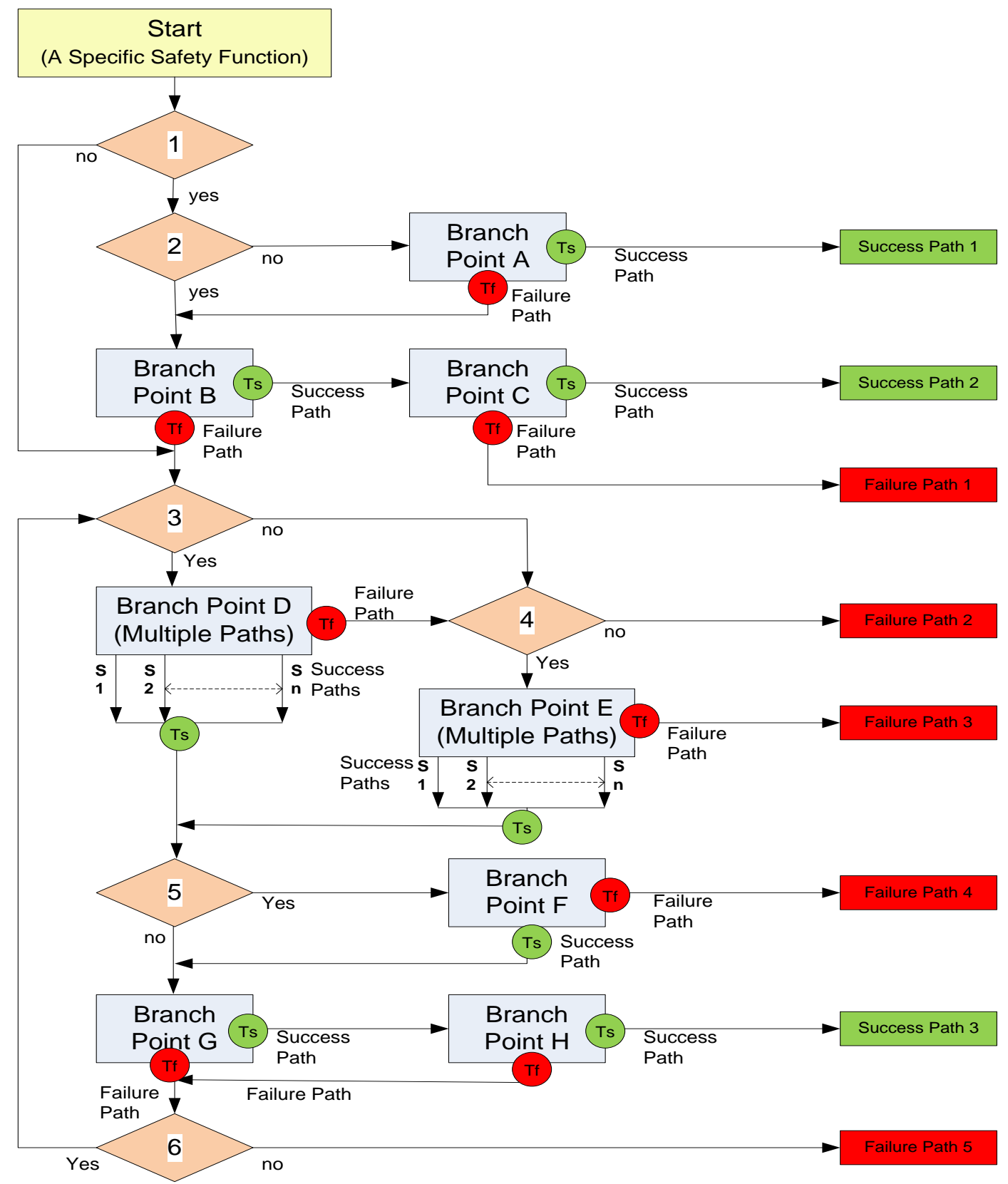

Figure 4-1: The CRT Construction Flowchart 
Hence, the flowchart has pruning rules incorporated into its design. Table 4-3 provides a detailed description of the flowchart questions while Table 4-4 gives the description of the success and failure paths for each branch point. In order to construct the CRT, the main inputs needed by the analyst include the HFE definition, identified safety function, crew and plant context, and all procedures used to carry out the safety function. The main output is a task decomposition of the safety function in the form of an ET, which can be used to find the failure and success paths, and the branch points of interest. This would aid in the HEP quantification.

The CRT construction flowchart (Figure 4-1) produces a skeleton CRT of the main branches in reference to the plant functions and procedural steps. The variations in scenarios due to the timing of the crew's response may also be included as branch points. Generally, the crew's response is considered to be either successful or not as represented in the CRT construction flowchart. In this case, timing is of no importance.

Table 4-3: CRT Flowchart Questions

\begin{tabular}{|c|c|c|}
\hline No. & Question & Description and Example \\
\hline 1 & $\begin{array}{l}\text { Is the specific function designed to } \\
\text { be initiated automatically? }\end{array}$ & $\begin{array}{l}\text { Auxiliary Feed Water is an example of safety function } \\
\text { designed to be initiated automatically. Isolation of a } \\
\text { steam generator is an example of a safety function that } \\
\text { is not designed to be initiated automatically. }\end{array}$ \\
\hline 2 & Is the scenario a fast transient? & $\begin{array}{l}\text { If loss of Main Feed Water occurs, the Auxiliary Feed } \\
\text { Water will be automatically initiated shortly thereafter. } \\
\text { Hence, Auxiliary Feed Water is a fast transient. }\end{array}$ \\
\hline 3.a & $\begin{array}{l}\text { Is there a procedure that includes } \\
\text { monitoring and operation of the } \\
\text { specific safety function? }\end{array}$ & The answer to this question is either a "yes" or "no". \\
\hline 3.b & $\begin{array}{l}\text { Is there a specific entry point in the } \\
\text { current procedure to a step to } \\
\text { manually initiate the safety function? }\end{array}$ & $\begin{array}{l}\text { If there is an entry point in the current procedure to a } \\
\text { step (or a supplemental procedure) to manually initiate } \\
\text { the safety function, the answer to this question will be } \\
\text { "yes". }\end{array}$ \\
\hline 4 & $\begin{array}{l}\text { Are there other procedural entry } \\
\text { points that lead to a step to manually } \\
\text { initiate the safety function? }\end{array}$ & $\begin{array}{l}\text { The answer is "yes" if there are additional entry points } \\
\text { in the current procedure (or another procedure to which } \\
\text { the operator is directed to) that includes a step to } \\
\text { manually initiate the safety function. }\end{array}$ \\
\hline 5 & $\begin{array}{l}\text { Are there any unexplored options } \\
\text { under } 3 . b \text { and } 4 \text { ? }\end{array}$ & $\begin{array}{l}\text { If there are other options in the procedure to lead the } \\
\text { operator to manually initiate the safety function, the } \\
\text { answer will be "yes". }\end{array}$ \\
\hline 6 & $\begin{array}{l}\text { Are there additional equipment and } \\
\text { manual actions that could be used to } \\
\text { provide the specific safety function? } \\
\text { This question refers to recovery } \\
\text { actions that the crew could } \\
\text { potentially take when everything else } \\
\text { fails. }\end{array}$ & $\begin{array}{l}\text { If there are other ways to achieve the same result as the } \\
\text { safety function, the answer to this question will be } \\
\text { "yes". If there are no opportunities for such recovery, } \\
\text { the answer will be "no". }\end{array}$ \\
\hline
\end{tabular}


Table 4-4: Detailed Description of the Success and Failure Paths for Each BP

\begin{tabular}{|c|c|c|}
\hline $\mathrm{BP}$ & Success Path & Failure Path \\
\hline A & $\begin{array}{l}\text { Operator manually initiates the safety function } \\
\text { before it is automatically initiated. }\end{array}$ & $\begin{array}{l}\text { Operator does not manually initiate the } \\
\text { safety function before it is automatically } \\
\text { initiated. }\end{array}$ \\
\hline B & The safety function is automatically initiated. & $\begin{array}{l}\text { The safety function is not automatically } \\
\text { initiated. }\end{array}$ \\
\hline $\mathrm{C}$ & $\begin{array}{l}\text { Operator does not manually turn off the } \\
\text { automatically initiated safety function. }\end{array}$ & $\begin{array}{l}\text { Operator manually turns off } \\
\text { automatically initiated safety function. }\end{array}$ \\
\hline $\mathrm{D}$ & $\begin{array}{l}\text { This branch point considers } \\
\text { whether the crew is in the correct procedure, } \\
\text { various options provided by the procedure for } \\
\text { success (i.e., multiple choices, each providing a } \\
\text { successful path to the critical step to manually } \\
\text { initiate the safety function, given the condition) } \\
\text { So this branch point may produce multiple } \\
\text { branches, each of which need to be pursued } \\
\text { separately in the CRT. The Success Path } \\
\text { corresponds to operator choosing a correct } \\
\text { option for the condition and manually initiating } \\
\text { the safety function. }\end{array}$ & $\begin{array}{l}\text { Operator is not in the correct procedure. } \\
\text { Operator is in the correct procedure but } \\
\text { chooses the wrong option for the condition, } \\
\text { resulting in failure to manually initiate the } \\
\text { safety function. }\end{array}$ \\
\hline $\mathrm{E}$ & imilar to Branch Point D. & Similar to Branch Point D. \\
\hline F & $\begin{array}{l}\text { Operator doesn't transfer to the wrong direction } \\
\text { from the exit point. }\end{array}$ & $\begin{array}{l}\text { Operator transfers to the wrong direction } \\
\text { from the exit point. }\end{array}$ \\
\hline $\mathrm{G}$ & $\begin{array}{l}\text { Safety function is not impaired by equipment } \\
\text { (hardware / system) failure. }\end{array}$ & $\begin{array}{l}\text { The safety function is impaired by non- } \\
\text { recoverable equipment (hardware / system) } \\
\text { failure. }\end{array}$ \\
\hline $\mathrm{H}$ & $\begin{array}{l}\text { Operators successfully initiate the safety } \\
\text { function manually. }\end{array}$ & $\begin{array}{l}\text { Operators failed to initiate the safety } \\
\text { function manually. }\end{array}$ \\
\hline
\end{tabular}

However, there are situations where the timing of the crew responses should be explicitly considered and these include: when timing has a significant impact on their next action or representation of their mental state; when there are competing events, i.e., situations where one action needs to be completed before the next one; when there are events in sequence, whether short or long duration; when the current event has an impact on future events. In order to explicitly consider timing in the CRT, each success path in the flow chart can be expanded into any of the paths as indicated in Figure 4-2. Also, each failure path can be expanded into any of the paths indicated in Figure 4-3. Therefore, instead of the conventional binary branches of the ET (which is generally used to represent the CRT when the timing of crew response is not of significant importance), an ET with more than two branches (up to 8 branches) at each branch point can be used when timing of crew responses that need to be incorporated into the CRT construction.

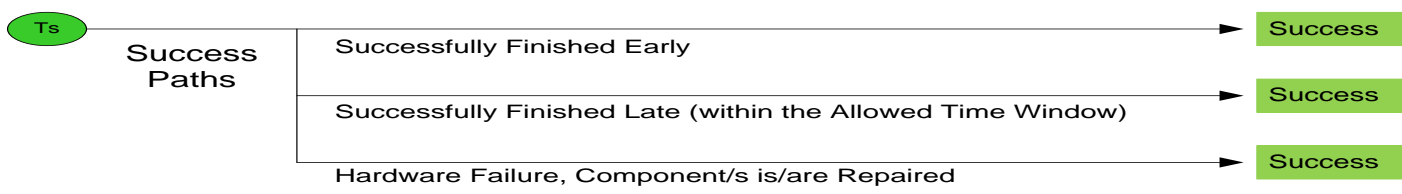

Figure 4-2: Timing in CRT Construction (Success Paths) 


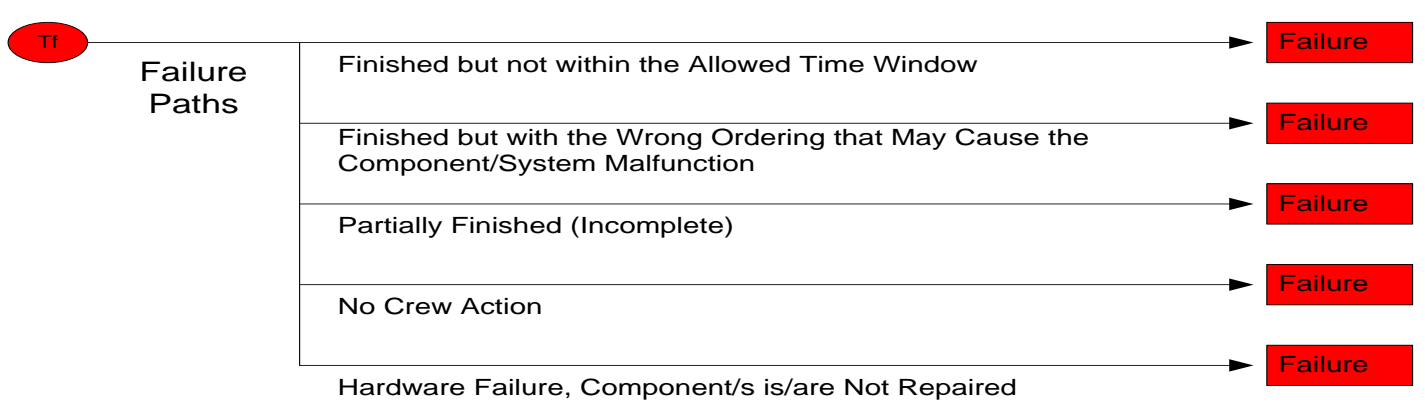

Figure 4-3: Timing in CRT Construction (Failure Paths)

Additional branch points can be introduced for explicit consideration of recovery from CFMs. Recovery refers to the possibility that the initial fault on the part of the crew may be corrected before the failure represented by the HFE occurs (i.e. it is internal to the evaluation of the HFE). In other words, before the cliff-edge at which no correction is possible, the crew is able to recognize that their response is not working and are able to do a mid-course correction.

Some of what could be called recovery is already included as one of the PIFs, a good example being the skill-of-the-craft implementation of searching for confirmatory indications, another being the existence of an alarm that is directly related to the required response. However, in general, the possibility of recovery from CFMs can be included as branches of the CRT. We refer to this as "global" recovery. An example is when the analysts can identify the possibility that new information comes into play once the crew has deviated from the required path. It is necessary to be clear what recovery mechanisms represented are already included in the definition of CFMs. This is because the ability of the crew to immediately realize and recover from an error while making it is incorporated in to the conditional probability estimates of the particular CFM. We refer to this as "local' recovery.

A high likelihood of recovery would generally be associated with scenario evolutions whose characteristics include [11]:

- The evolution of the plant status, as determined by parameters that the crew is expected to be monitoring subsequent to the error they have made, and it should be sufficiently at odds with the mental picture of the plant in order to create a need to reassess whether their response is the correct one;

- The newly revealed plant status is such that there is a plan or procedural path for correct response given a revised mental model;

- The arrival of the new information and its assimilation can happen in sufficient time to allow the correct response to be effective and prevent the HFE.

As indicated earlier, the CRT Flowchart methodology covers a case where the HFE is associated with a specific safety function in the context of a defined PRA scenario. The different "function-level" CRT modules can be assembled through simple merge rules to build larger and more comprehensive CRTs [10]. For example assume that the function "Secondary Heat Sink Control (SHSC)" is represented by CRT module 1, "Feed" is represented by CRT module 2 and "Bleed" is represented by CRT module 3 as indicated in Figure 4-4. Also, assume that the "success" end state in CRT module 1 is "Feed". The CRT flowchart can be used to construct a CRT with "Feed" as the safety function (i.e. CRT module for function 2). Also, assuming that the "success" end state in CRT module 2 is "Bleed", the CRT flowchart can also be used to construct a CRT with "Bleed" as the safety function (i.e. CRT module for function 3). Therefore, two or more CRT modules can be connected together to form a much larger and more comprehensive CRT, covering the full range of an accident timeline and possible scenarios as reflected in the PRA model.

The following guidelines could serve as CRT merge rules, i.e., in aiding the analyst to determine when to continue or stop developing the next CRT module from the end state of the present CRT [11].

- If there is a "success" end state, use it as the safety function in developing the connecting CRT. 
- If there is an option for recovery, use that end state as the safety function in developing the connecting CRT.

- If there is a "failure" end state and no option for recovery, then stop at that point and do not develop the connecting CRT.

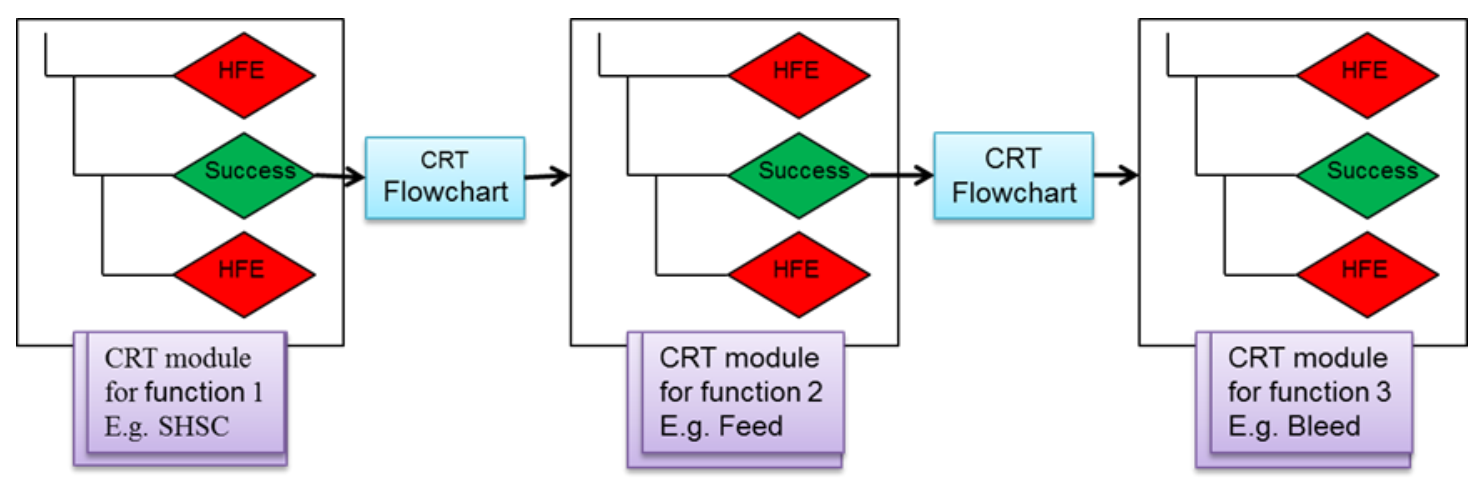

Figure 4-4: Linking of function-level CRT modules to form a large CRT

\section{Step 2.C: Prune / Simplify the CRT}

In addition to deciding which branches to keep in the CRT and ultimately quantify, analysts may decide that it is reasonable to collapse some of the separate nodes or branches into a single node for quantification purposes. It may initially be reasonable to break-out the various failure paths to a detailed level. However, it may be decided later on that the cues and related decisions for some steps in the procedures create a dependency between the steps or imply that the steps should be integrated for quantification purposes. Thus, it may make sense to cluster and quantify the branches together. Also, we note that new HFEs can be added to the PRA model if this becomes necessary.

\subsection{Step 3: Identification of Crew Failure Modes for CRT Branches}

A set of CFMs (Table 4-5) is proposed to further specify the possible forms of failure in each of the Information, Decision and Action (IDA) phases (i.e. they represent the manner in which failures occur in each IDA phase). CFMs are the generic functional modes of failure of the crew in its interactions with the plant and represent the manifestation of the crew failure mechanisms and proximate causes of failure. They are selected to cover the various modes of operator response including Procedure Driven (PD), Knowledge Driven (KD), or a Hybrid of both (HD). In the PD mode, CFMs are selected to represent how the subtasks typically found in operating procedures in nuclear power plants can be viewed by an observer who has an understanding of the crew's expected response to a particular emergency situation. In order to avoid double counting crew failure scenarios during the estimation of Human Error (HEPs), the CFMs are defined as being mutually exclusive or orthogonal.

Table 4-5 shows the set of CFMs, with each defined based on the particular IDA phase in which it occurs. 19 main CFMs have been defined (9 in the "I" phase, 7 in the "D" phase and 3 in the "A" phase). It was developed based on aggregated information from nuclear industry operating experience, relevant literature on crew error modes in nuclear power plants, discussions with plant operators and experts, error modes defined in the US Nuclear Regulatory Commission's (NRC's) Scenario Authoring, Characterization, and Debriefing Application (SACADA) database project [16]. Note that the SACADA database project which is a part of the US NRC's HRA data program [17] is an ongoing data collection effort sponsored by the US NRC and aimed at collecting human performance data / information for use in human reliability applications. The error modes from this database were incorporated into this CFM set in order to provide the necessary statistical basis needed by the Phoenix methodology when the database matures in the future. Refer to [11] for definitions of each CFM. 
Table 4-5: Set of CFMs [11]

\begin{tabular}{|c|c|c|c|c|c|}
\hline ID & $\begin{array}{l}\text { CREW FAILURE } \\
\text { MODES IN "I" PHASE }\end{array}$ & ID & $\begin{array}{l}\text { CREW FAILURE } \\
\text { MODES IN "D" } \\
\text { PHASE }\end{array}$ & ID & $\begin{array}{l}\text { CREW FAILURE } \\
\text { MODES IN "A" PHASE }\end{array}$ \\
\hline I1 & $\begin{array}{l}\text { Key Alarm not Responded } \\
\text { to (intentional \& } \\
\text { unintentional) }\end{array}$ & D1 & $\begin{array}{l}\text { Plant/System State } \\
\text { Misdiagnosed }\end{array}$ & A1 & Incorrect Timing of Action \\
\hline $\mathbf{I 2}$ & $\begin{array}{l}\text { Data Not Obtained } \\
\text { (Intentional) }\end{array}$ & D2 & Procedure Misinterpreted & $\mathbf{A 2}$ & $\begin{array}{l}\text { Incorrect Operation of } \\
\text { Component/Object }\end{array}$ \\
\hline I3 & Data Discounted & D3 & $\begin{array}{l}\text { Failure to Adapt } \\
\text { Procedures to the } \\
\text { situation }\end{array}$ & $\mathbf{A 3}$ & $\begin{array}{l}\text { Action on Wrong } \\
\text { Component / Object }\end{array}$ \\
\hline I4 & $\begin{array}{l}\text { Decision to Stop } \\
\text { Gathering Data }\end{array}$ & D4 & $\begin{array}{l}\text { Procedure Step Omitted } \\
\text { (Intentional) }\end{array}$ & & \\
\hline I5 & Data Incorrectly Processed & D5 & $\begin{array}{l}\text { Inappropriate Transfer to } \\
\text { a Different Procedure }\end{array}$ & & \\
\hline I6 & Reading Error & D6 & Decision to Delay Action & & \\
\hline I7 & $\begin{array}{l}\text { Information } \\
\text { Miscommunicated }\end{array}$ & D7 & $\begin{array}{l}\text { Inappropriate Strategy } \\
\text { Chosen }\end{array}$ & & \\
\hline I8 & $\begin{array}{l}\text { Wrong Data Source } \\
\text { Attended to }\end{array}$ & & & & \\
\hline I9 & $\begin{array}{l}\text { Data Not Checked with } \\
\text { Appropriate Frequency }\end{array}$ & & & & \\
\hline
\end{tabular}

The CRT branches and sequences capture some, but not all of the contextual factors and causes of crew error. In order to simplify the modeling process and analysis, the CRT branches are defined at the functional level and therefore; do not cover the human failure mechanisms or their causes [14]. HFEs or contributing causes can be traced through the Information, Decision, and Action (IDA) chain using the information-processing model. An error (which is the mismatch between the crew's action and plant need) could therefore be rooted in (1) action execution failure, A, given correct decision; (2) failure in situation assessment, problem solving and decision making, given correct information, D; or (3) failure in the information-gathering stage, I. Error is being defined in terms of the crew failing to meet the needs of the plant (and this is typically related to a required safety function) with focus on the functional impact of crew actions. It may be identical to HFEs defined in PRAs (as top events in the event tree or basic event in the fault tree) or one of the corresponding causes. Therefore, the "minimal cut-sets" of the human failure events are the failures in I, D, or A phases. This logic, represented in the form of a fault tree [10] is shown in Figure 4-5.

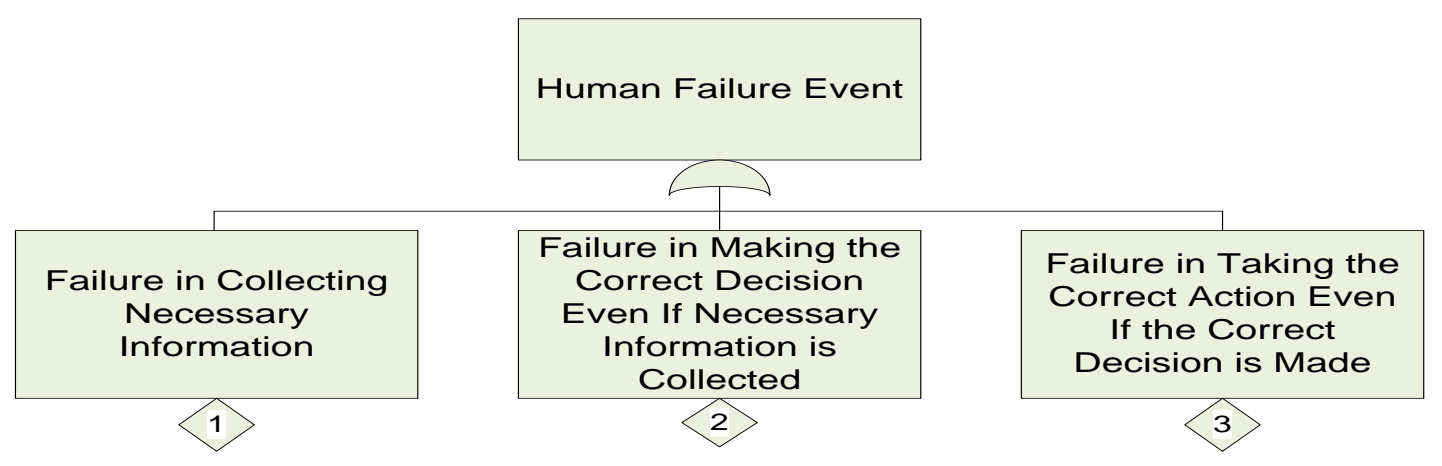

Figure 4-5: HFE logic in terms of IDA phases 
Potentially, all CFMs are relevant to each CRT branch point (and associated HFEs). However, when the analysis is conducted in the context of a scenario, and depending on the I-D-A phase, only a subset of the CFMs will apply. Therefore, a set of Fault trees (FTs) were introduced [14], [18] to aid the analysts in the selection of the relevant CFMs for each branch point within each scenario. These fault trees were developed in order to bridge the gap between the fields of HRA and psychology/human factors and they are based on salient information from cognitive psychology literature. These trees have been expanded to include the proposed set of CFMs and restructured [11] to enhance clarity and consistency and to serve as a guide to the analyst in the CFM selection process.

The simplified cognitive model used in the FTs has three main parts as represented in Figure 4-5. Each part is further broken down into FTs (Figure 4-6 through Figure 4-10) and based on the context related to the CRT branch point assessed, the analyst will trace through until eventually encountering an end point in the trees which represents the CFM associated with the branch point. The CFMs form the basic events in the FTs, i.e., lowest level of the FTs with small circles underneath it. In some instance, a CFM can occur when the crew is following procedure and also relying on their knowledge. The crew can also switch between the procedure mode (following procedure as the strategy) and knowledge mode (relying on their knowledge as the strategy) during a specific event. The inputs needed by the analyst in order to apply the FT include: HFE definition; identified safety function; plant context; crew context; developed CRT; and identified critical paths in the CRT.

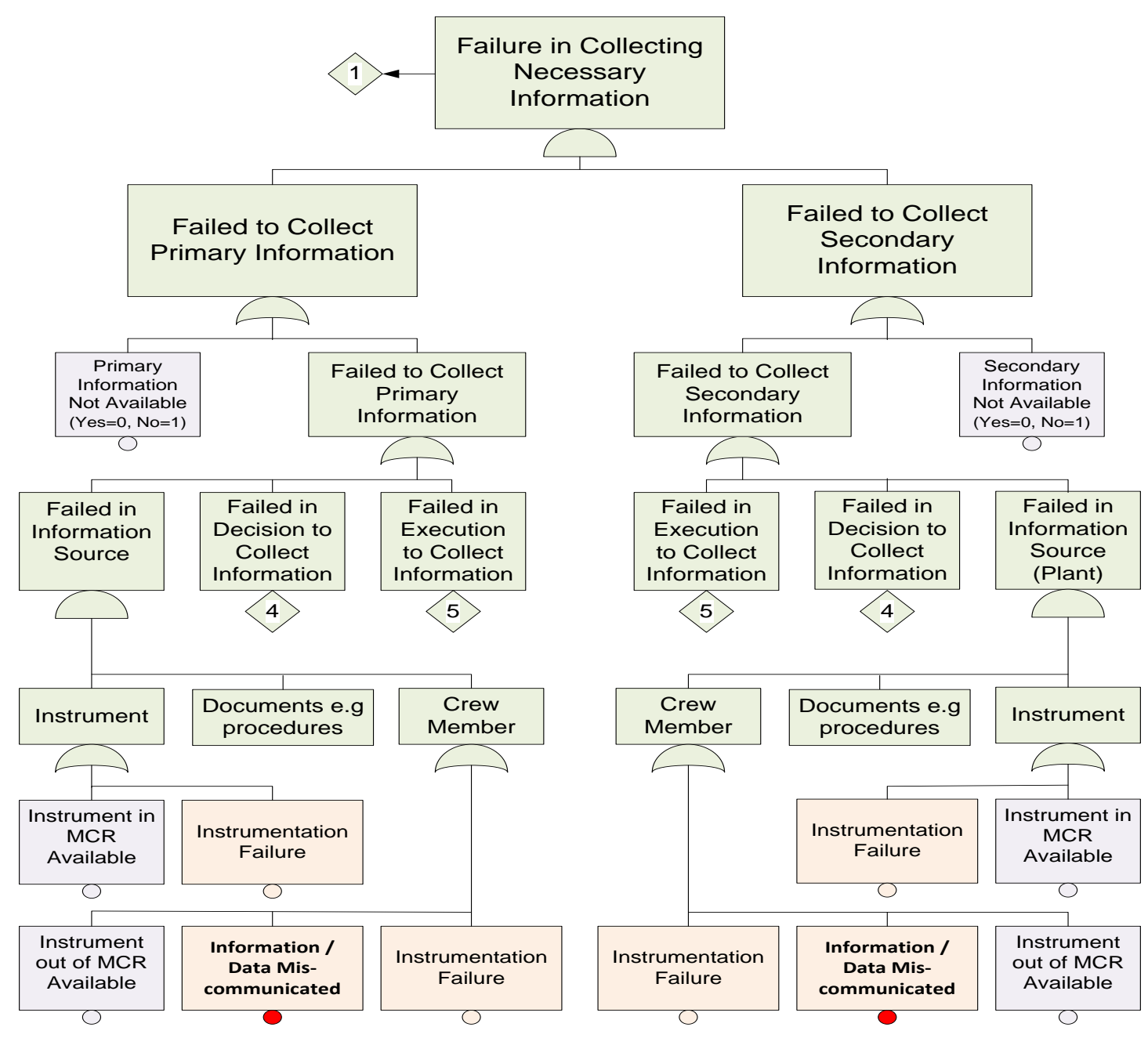

Figure 4-6: Extension of HFE fault tree covering Failure in Collecting Necessary Information 


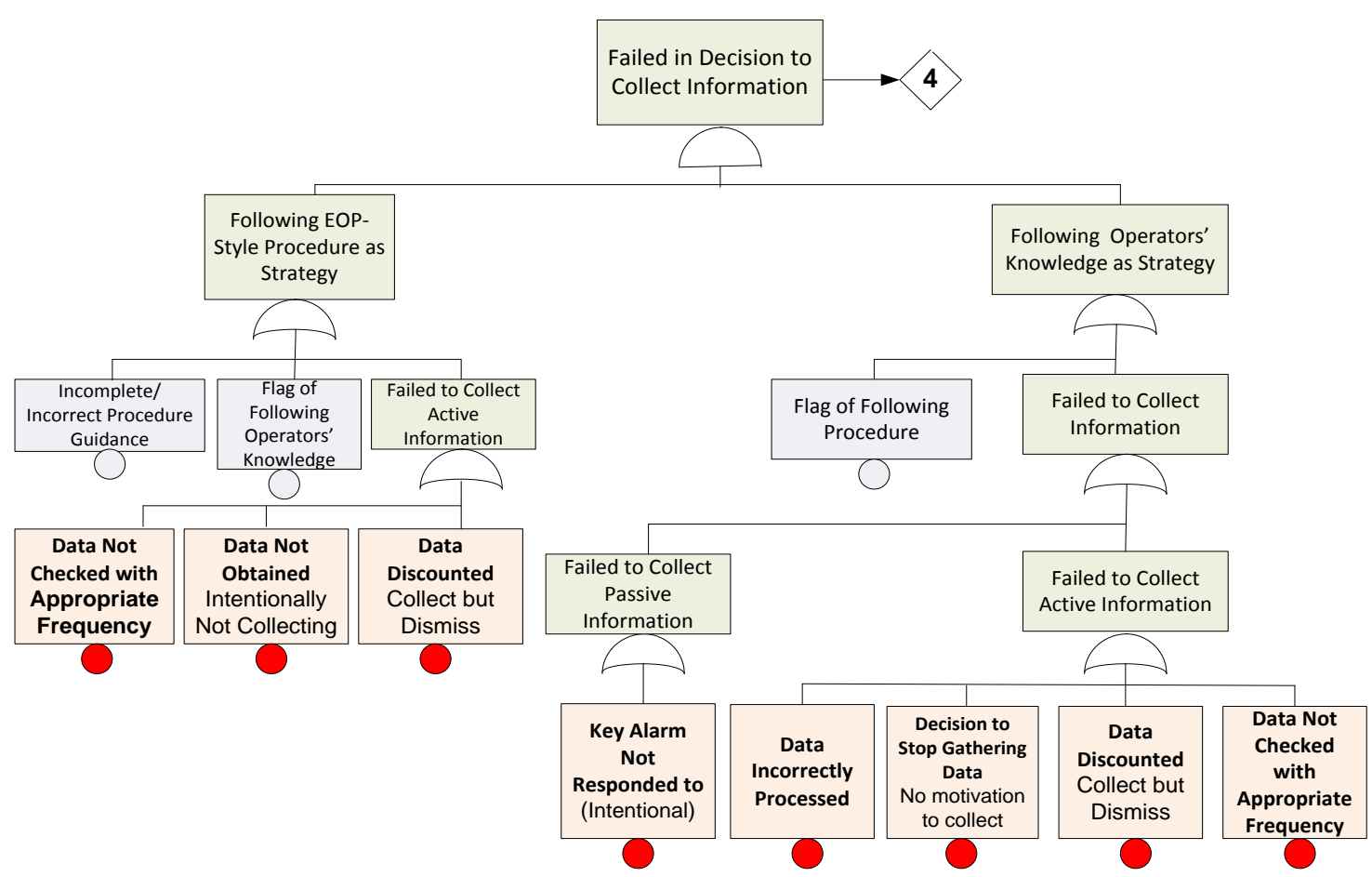

Figure 4-7: Extension of Fault Tree covering Failure in Decision to Collect Information

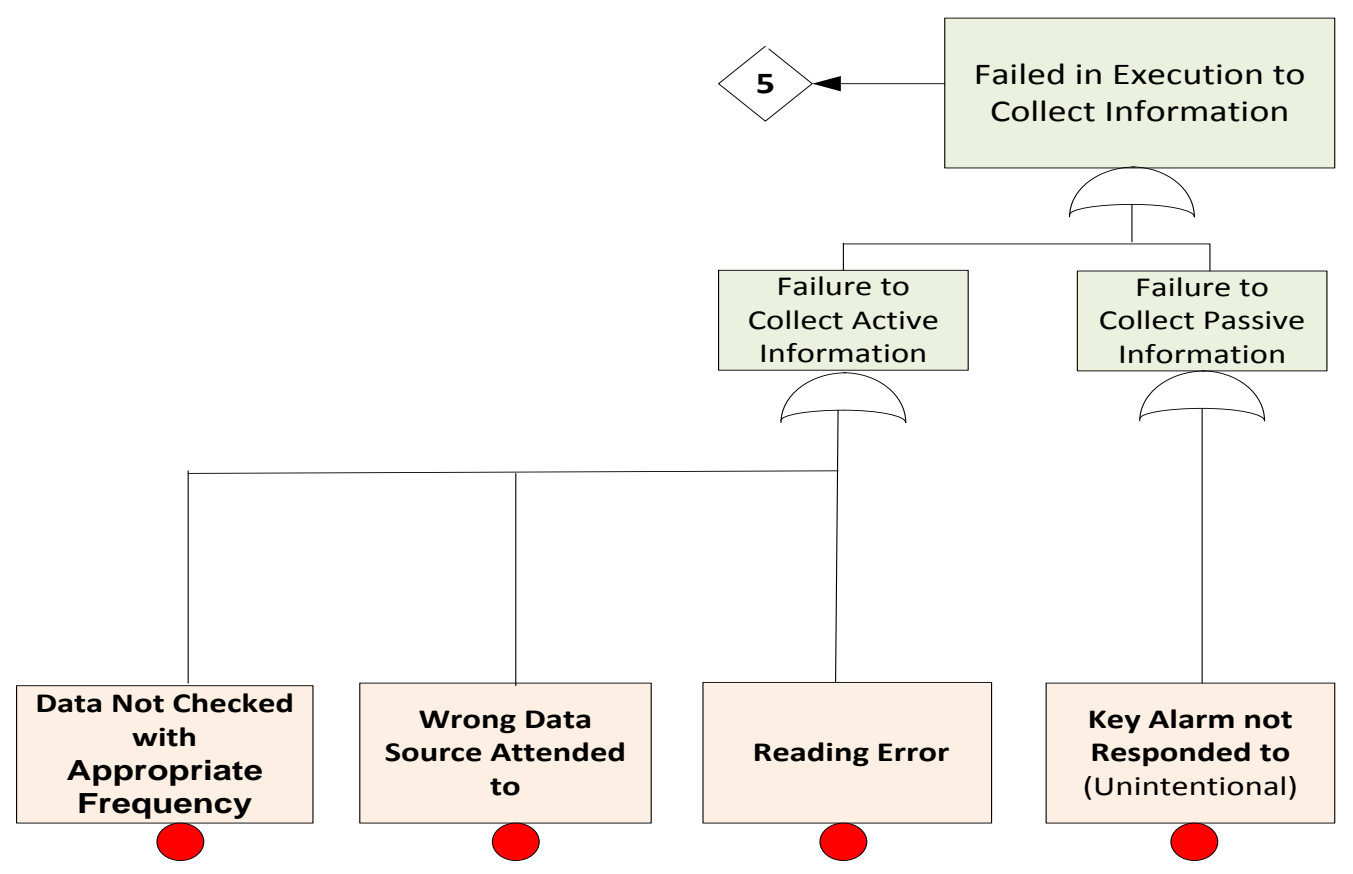

Figure 4-8: Extension of Fault Tree covering of in Execution to Collect Information 


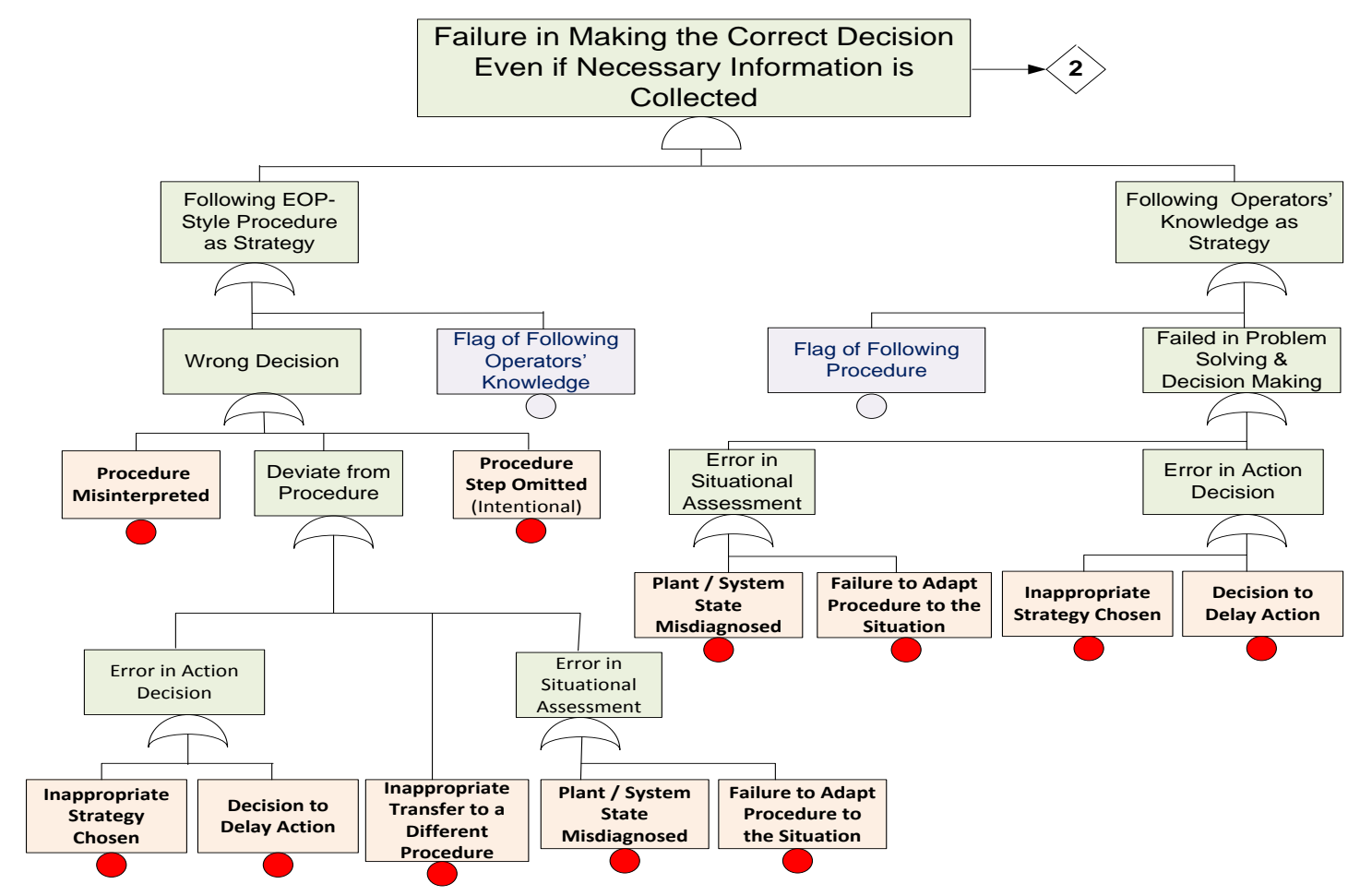

Figure 4-9: Extension of Fault Tree covering Failure in Making the Correct Decision

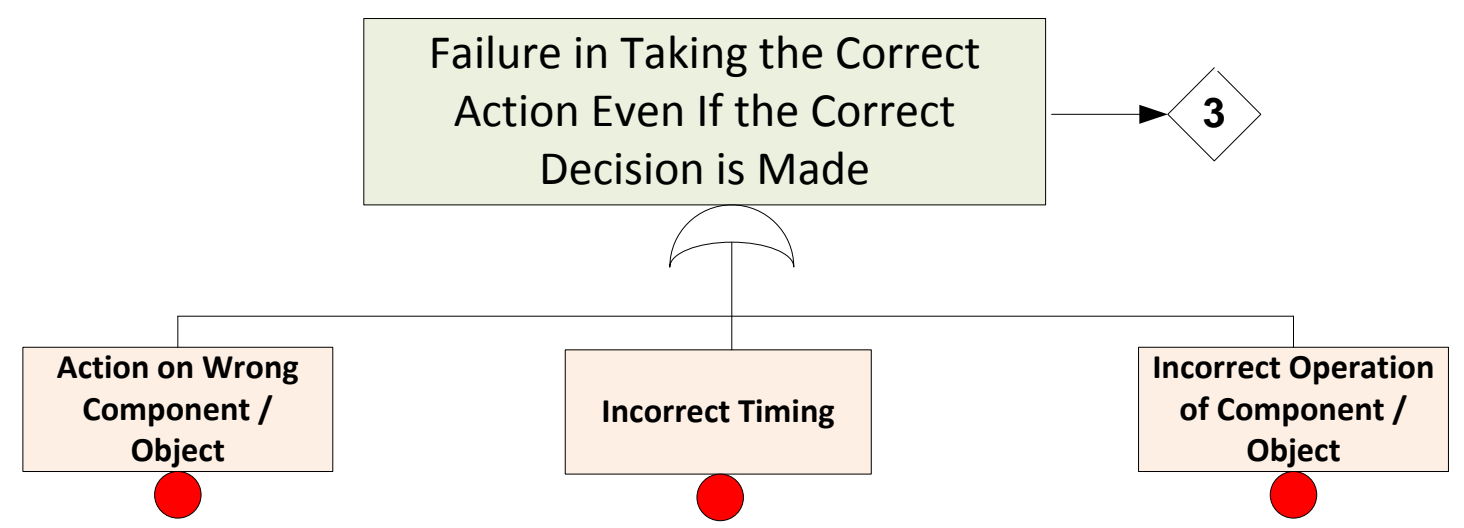

Figure 4-10: Extension of Fault Tree covering Failure in Taking the Correct Action

\subsection{Step 4: Establishing Relation Between CFMs and PIFs}

The CFMs are linked to the PIFs (which form the third layer of the framework). The CFM- PIF linkage is modeled using a Bayesian Belief Network (BBN) as shown in Figure 4-11. A BBN is a type of probabilistic network that consist of a set of nodes which represent variables and set of directed arcs representing the direct causal relationships between the nodes [20], [21]. BBNs are becoming popular in risk and reliability analysis disciplines to represent non-deterministic causal relations, provide a mechanism to incorporate both qualitative and quantitative information from different sources for analysis, and provide the flexibility of updating the model (present state of knowledge) to incorporate new evidence as they become available. BBNs are a specific type of causal models and they are used to capture the stochastic and uncertain characteristics of a system. They provide a causal structure used for modeling interdependences among elements of the system. This causal structure can be used for causal, evidential reasoning and inter-causal reasoning [21]. 
Two main steps are involved in the development of a BBN causal model. The first step is the identification of the variables to be included as nodes in the model. The second step involves the identification of the relationships between the nodes using arcs with arrow heads indicating the direction of influence. In this case, the two main groups of variables to be included as nodes are PIFs and CFMs since the primary purpose of our BBN is to model the effect of the PIFs on the CFMs. The relationship between the CFMs and PIFs which indicate the path of influence of the nodes on each other is based on the CFM - PIF framework [11]. Note that the PIFs used in Phoenix model have been grouped and divided into 3 levels (Table 4-6). This grouping and hierarchy is depicted in Figure 4-11. The CFM nodes are shown in green, level PIFs in blue, level 2 PIFs in brown and level 3 PIFs in orange color. Note that Figure 4-11 is meant to illustrate the PIF hierarchy and the relationship to the CFMs. Refer to Table 4-5 for the complete set of CFMs and Table 4-6 for the PIF groups and hierarchy.

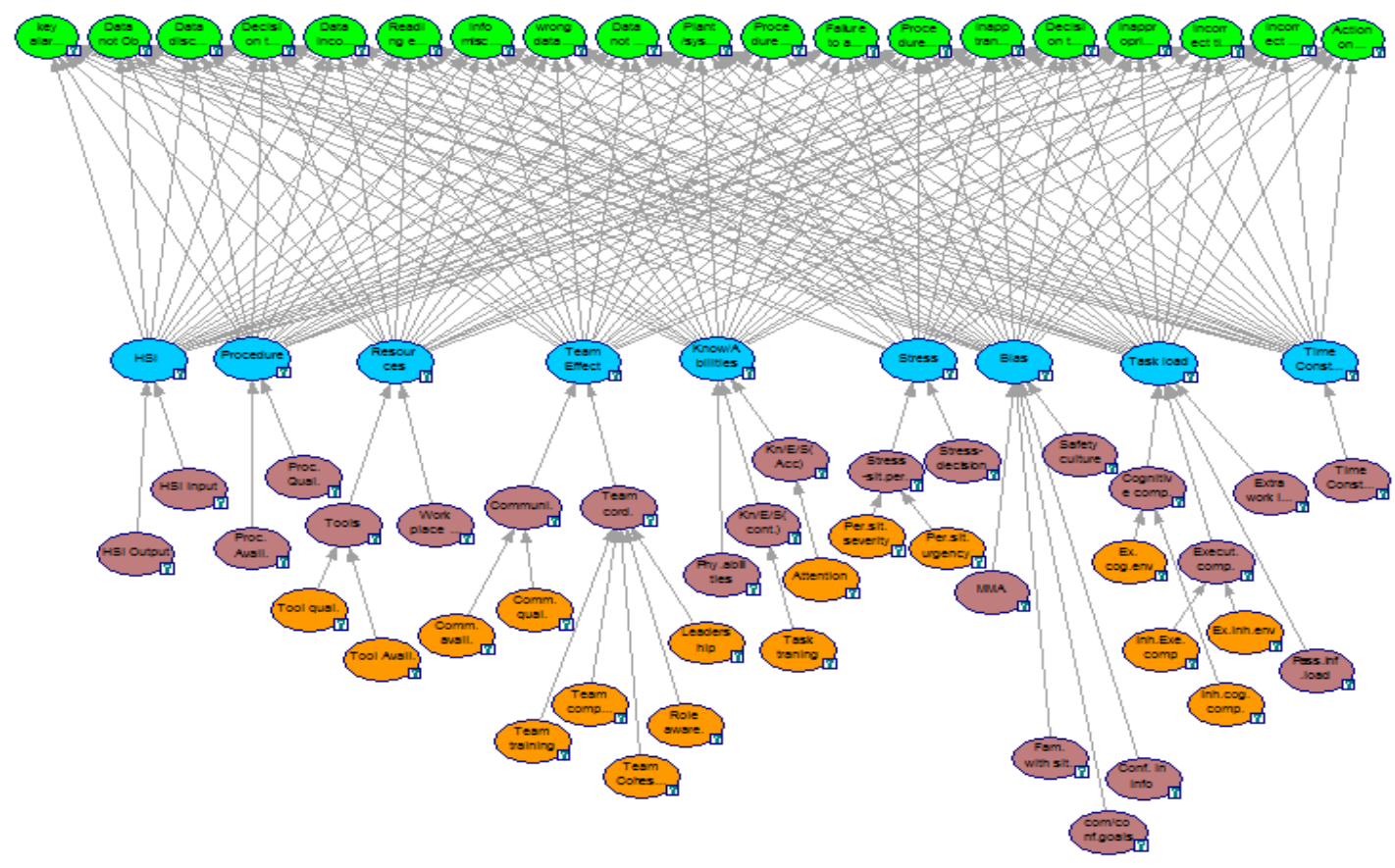

Figure 4-11: Master CFM - PIF BBN Model

The PIFs form the bottom layer of the qualitative analysis framework. As part of this work, a PIF grouping and hierarchy was developed by aggregating information various sources including: a set of PIFs proposed by K.M. Groth [22], [23], IDAC [24]; those used in other HRA methods including SPAR-H [5], CREAM [4], HEART [2], [25], THERP [1]; the US NRC's Good practice for HRA [26]; the Human Event Repository and Analysis (HERA) database [27], [28]; and error causes from the US Nuclear Regulatory commission's (NRC's) Scenario Authoring, Characterization, and Debriefing Application (SACADA) database project [16]. Our final PIF set (Table 4-6) is grouped in terms of their impact on operating crew behavior. The PIFs are divided into groups and classified into levels within the groups, therefore forming a hierarchical structure which can be fully expanded (e.g. in applications where every factor can be explicitly identified like in computer modeling) or collapsed (where high level factors are required which may be due to lack of data to support the lower level factors as is the case with many HRA methods). 
Table 4-6: Proposed PIF Groups and Hierarchy [11]

\begin{tabular}{|c|c|c|c|c|c|c|c|c|}
\hline \multicolumn{9}{|c|}{ PIF GROUPS \& HIERARCHY } \\
\hline$\underline{\mathrm{HSI}}$ & Procedures & Resources & $\begin{array}{c}\text { Team } \\
\text { Effectiveness }\end{array}$ & $\frac{\text { Knowledge/ }}{\text { Abilities }}$ & Bias & $\underline{\text { Stress }}$ & Task Load & $\begin{array}{l}\underline{\text { Time }} \\
\text { Constraint }\end{array}$ \\
\hline $\begin{array}{l}\text { HSI } \\
\text { Input }\end{array}$ & $\begin{array}{l}\text { Procedure } \\
\text { Quality }\end{array}$ & Tools & Communication & $\begin{array}{l}\text { Knowledge/ } \\
\text { Experience/ } \\
\text { Skill } \\
\text { (Content) } \\
\end{array}$ & $\begin{array}{l}\text { Morale/ } \\
\text { Motivation/ } \\
\text { Attitude }\end{array}$ & $\begin{array}{l}\text { Stress due } \\
\text { to Situation } \\
\text { Perception }\end{array}$ & $\begin{array}{l}\text { Cognitive } \\
\text { Complexity }\end{array}$ & $\begin{array}{l}\text { Time } \\
\text { Constraint }\end{array}$ \\
\hline \multirow[t]{8}{*}{$\begin{array}{l}\text { HSI } \\
\text { Output }\end{array}$} & $\begin{array}{l}\text { Procedure } \\
\text { Availability }\end{array}$ & $\begin{array}{l}\text { Tool } \\
\text { Availability }\end{array}$ & $\begin{array}{l}\text { Communication } \\
\text { Quality }\end{array}$ & Task Training & $\begin{array}{l}\text { Safety } \\
\text { Culture }\end{array}$ & $\begin{array}{l}\text { Perceived } \\
\text { Situation } \\
\text { Urgency }\end{array}$ & $\begin{array}{l}\text { Inherent } \\
\text { Cognitive } \\
\text { Complexity }\end{array}$ & \\
\hline & \multirow{2}{*}{\multicolumn{2}{|c|}{$\begin{array}{l}\text { Work Place } \\
\text { Adequacy }\end{array}$}} & \multirow[t]{2}{*}{$\begin{array}{l}\text { Communication } \\
\text { Availability }\end{array}$} & $\begin{array}{l}\text { Knowledge/ } \\
\text { Experience/ } \\
\text { Skill (Access) }\end{array}$ & $\begin{array}{l}\text { Confidence } \\
\text { in } \\
\text { Information }\end{array}$ & $\begin{array}{l}\text { Perceived } \\
\text { Situation } \\
\text { Severity }\end{array}$ & $\begin{array}{l}\text { Cognitive } \\
\text { Complexity } \\
\text { due to } \\
\text { External } \\
\text { factors }\end{array}$ & \\
\hline & & & & Attention & $\begin{array}{l}\text { Familarity } \\
\text { with or } \\
\text { Recency of } \\
\text { Situation }\end{array}$ & $\begin{array}{l}\text { Stress due } \\
\text { to Decision }\end{array}$ & $\begin{array}{l}\text { Execution } \\
\text { Complexity }\end{array}$ & \\
\hline & & & Leadership & $\begin{array}{l}\text { Physical } \\
\text { Abilities and } \\
\text { Readiness }\end{array}$ & $\begin{array}{l}\text { Competing } \\
\text { or } \\
\text { Conflicting } \\
\text { Goals }\end{array}$ & & $\begin{array}{l}\text { Inherent } \\
\text { Execution } \\
\text { Complexity }\end{array}$ & \\
\hline & & & Team Cohesion & & & & $\begin{array}{l}\text { Execution } \\
\text { Complexity } \\
\text { due to } \\
\text { External } \\
\text { factors }\end{array}$ & \\
\hline & & & Role Awareness & & & & $\begin{array}{l}\text { Extra Work } \\
\text { Load }\end{array}$ & \\
\hline & & & $\begin{array}{l}\text { Team } \\
\text { Composition }\end{array}$ & & & & $\begin{array}{l}\text { Passive } \\
\text { Information } \\
\text { Load }\end{array}$ & \\
\hline & & & Team Training & & & & & \\
\hline \multirow[t]{4}{*}{ KEY } & \multicolumn{2}{|c|}{ MEANING } & & & & & & \\
\hline & \multicolumn{2}{|c|}{ Level 1 PIFs } & & & & & & \\
\hline & \multicolumn{2}{|c|}{ Level 2 PIFs } & & & & & & \\
\hline & \multicolumn{2}{|c|}{ Level 3 PIFs } & & & & & & \\
\hline
\end{tabular}

In the definition of the PIFs, three aspects are considered which include its: nature (i.e. its inborn or inherent qualities); attributes (i.e. characteristics or qualities associated with or used to describe it); and influence on other PIFs and / or performance (i.e. how it affects or impacts other PIFs or human performance) [11].

- Human System Interface (HSI) Group: It refers to the ways and means of interaction between the crew and the system. This PIF covers the quality (usability, ergonomics, physical access, etc) of the HSI [29] both in terms of system output as well as the crew's input to the system.

- Procedures Group: As a PIF, procedures refer to the availability and quality of the explicit stepby-step instructions needed by the crew to perform a task. Ideally, no errors should be committed by the crew when they are following the procedure correctly. However, procedures could be 
written incorrectly and therefore lead the crew to make errors even with the right intent. This group is made up of two level 2 PIFs namely: Procedure Quality and Procedure Availability.

- Resources Group: This PIF refers to the availability and adequacy of the required resources which are necessary to aid the crew in completing their assigned task. Resources are provided by the organization to the crew.

- Team Effectiveness: As a PIF, it refers to the degree of harmonization and synchronization of crew member's contribution to the team's overall goals and team tasks. The team in this context refers to a group of persons working together to achieve a common goal or purpose. In order to work together as a unit, an effective team needs to be properly coordinated and have ability to adequately exchange information between its members.

- Knowledge / Abilities Group: This PIF refers to the adequacy of knowledge and abilities of the crew. In order to perform an assigned task, the crew needs to possess the required knowledge (understanding of the system and task to be performed) [29], [30], experience (accumulation of the knowledge gained over time through training and previous interactions with the system) [31], [32], skill (ability to perform the necessary task related activities with little cognitive effort) [33], the ability to access it when needed, and also the required physical ability. It is difficult to separate knowledge from experience because experience is partly gained by putting the knowledge acquired into practice. However, less experienced personnel are not necessarily less knowledgeable than their more experienced counterparts [22] and vice-versa.

- Bias Group: This PIF refers to the crew's tendency to make decisions or reach conclusions based on selected pieces of information while excluding information that doesn't agree with the decision or conclusion. Bias may appear in the form of confirmation bias, (i.e., only selecting the piece of information that supports one's hypothesis), belief bias, (i.e., only selecting the piece of information that reinforces one's own personal beliefs), and averaging bias (regression toward the mean) [34], [35]. Bias may result from such factors as previous experiences, familiarity with a certain situation, competing goals, personal motivation, morale and attitude. Bias can also be externally-induced such as preferences or inclinations in judgment encouraged or imposed by the team leader, organizational culture, or a recognized authority. Extreme bias becomes fixation, which could induce systematic errors.

- Stress Group: As a PIF, stress refers to the tension / pressure [1] induced on the crew by their perception of the situation [36] or by the awareness of the consequences and responsibility that comes along with the decisions they make.

- Task Load Group: This PIF refers to the load induced on the crew by the actual demands of the assigned task in terms of the complexity of the task, quantity, importance, accuracy requirements per unit of time. The perceived level of this load is dependent on the proficiency level of the crew and their level of familiarity with the tasks [24]. It is also acknowledged that there may be cases where having too few tasks can lead to errors due to the crew's complacency. Task load is a component of the perceived workload [33], and the term "workload" seen in literature generally has a broader meaning than task load [37].

- Time Constraint Group: As a PIF, time constraint refers to the crew's perception of the adequacy of the time available to complete the task at hand. It involves both the real duration of the task (which is the amount of time required to complete the task) and the perceived time (which is the crew's estimate of the available time). Obviously, there is the real duration (i.e. actual time required) and then the crew's perception of that time. This perception of time can affect the crew's stress level if it is estimated to be inadequate [38].

\subsection{Step 5: Development of CRT Scenario for HFE(s) \\ Step 5.A: Model Integration}

As discussed previously, the qualitative analysis framework has three layers. The Crew Response Tree (CRT) forms the top layer. The Information, Decision, and Action (IDA) model for crew errors using Fault Trees (FTs) forms the second layer. This approach of linking the FTs to the CRT will help identify the crew-plant interaction scenario cut-sets. 
The Crew Failure Mode (CFM) nodes in the Master Bayesian Belief Network (BBN) model and the CFM basic events in the FTs associated with branch points of the CRT are obviously the connection between the PIF hierarchy and the rest of the qualitative analysis modules. These three layers (CRT, FT \& BBN) are combined together to form the integrated model illustrated in Figure 4-12. By this illustration, the Human Failure Event (HFE) scenarios identified through the CRT and CFM fault trees are now extended to include the last layer of "causal factors" (i.e. the set of PIFs). The path through this integrated model gives the details of how the entire story needs to be narrated and read. Subscenarios are strings which are combined to provide the detail narratives and qualitative insights into the analysis. The logic model is used to tie together all the conditionalities that appear in the scenarios.

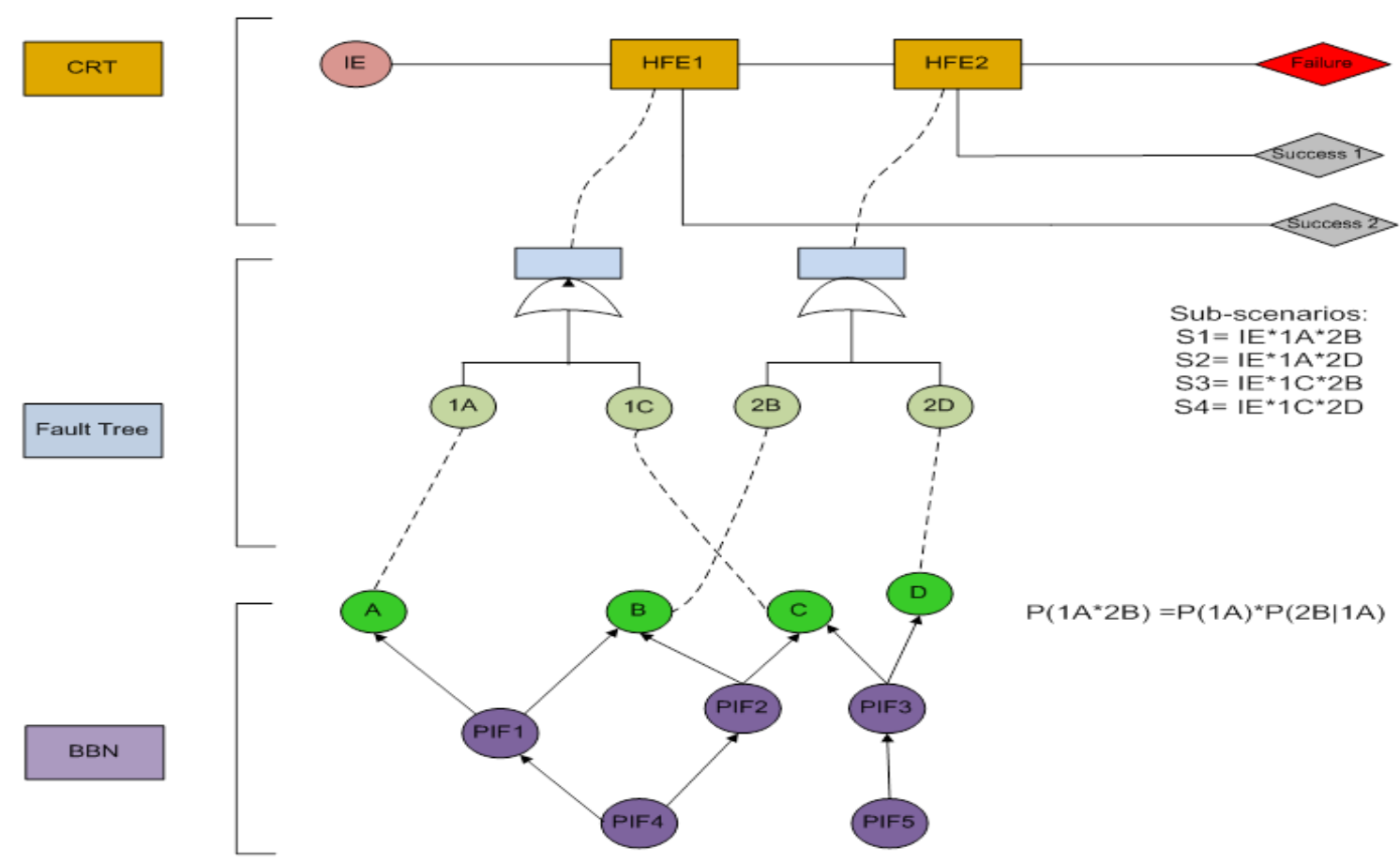

Figure 4-12: Sample diagram of the Integrated Model

\section{Step 5.B: Model Interpretation}

For each of the CRT scenarios, the "context" of an HFE to be captured by the qualitative analysis through the CRT and other layers of the methodology include: the portion of the specific PRA ET scenario(s) that lead to the HFE of interest; the corresponding time from the start of the scenario; the portion of the specific CRT scenario that leads to the HFE; and all other relevant plant and crew "factors" not shown on the ET and CRT. For each HFE, the analyst can develop a narrative version, clearly describing the causal chain and the role of various context factors leading up to the HFE.

\section{CONCLUDING REMARKS}

In the paper, we have provided a summary of the steps and techniques of performing the qualitative analysis using the Phoenix HRA methodology. This is accomplished with the aid of various modeling tools which include Crew Response Tree (CRT) flowcharts, CRTs, Fault Trees (FTs), (Crew Failure Mode - Performance Influencing Factor (CFM-PIF) tables, and Bayesian Belief Network (BBNs). When properly applied, Phoenix methodology should produce a more extensive analysis with broader considerations for the conditions that could lead to crew failure. Also, it should produce a detailed, consistent, traceable, reproducible and properly documented HRA qualitative analysis. This would aid 
in addressing some of the current issue facing the field of HRA and hence, PRAs in general. Several applications and detailed examples are provided in [11] as well as forthcoming papers by the authors.

\section{ACKNOWLEDGMENT}

This work was partially funded through a Collaborative Research Grant (NRC-04-09-143) between the U.S. Nuclear Regulatory Commission (USNRC) and the Center for Risk and Reliability of the University of Maryland. A number of individuals made significant contributions to the development of the original idea of the Phoenix approach into a full methodology and demonstration of its applications. These include the late Dr. Dana Kelly, Dr. Katrina Groth, and Ms. Johanna Oxstrand. USNRC also partially supported the contributions of Johanna Oxstrand at Idaho National Laboratory, a multi-program laboratory operated by Battelle Energy Alliance for the United States Department of Energy.

\section{REFERENCES}

[1] A. D. Swain and H. E. Guttman, "Handbook of Human Reliability Analysis with Emphasis on Nuclear Power Plant Applications," US Nuclear Regulatory Commission, Washington, DC, Tech. Rep. NUREG/CR-1278, 1983.

[2] J. Williams, "HEART: A proposed method for assessing and reducing human error," Advances in Reliability Technology Symposium $\left(9^{\text {th }}\right)$, University of Bradford, 1986.

[3] D. Embrey, P. Humphreys, E. Rosa, B. Kirwan, and K. Rea, "SLIM-MAUD: an approach to assessing human error probabilities using structured expert judgment," US Nuclear Regulatory Commission, Washington, DC, Tech. Rep. NUREG/CR-3518, 1984.

[4] E. Hollnagel, Cognitive reliability and error analysis method (CREAM), 1 ed. Amsterdam, Netherlands: Elsevier, 1998.

[5] D. Gertman, H. Blackman, J. Marble, J. Byers, and C. Smith, "The SPAR-H Human Reliability Analysis method," US Nuclear Regulatory Commission, Washington, DC, Tech. Rep. NUREG/CR-6883, 2005.

[6] A. Mosleh and J. Y. H. Chang, "Cognitive modeling and dynamic probabilistic simulation of operating crew response to complex system accidents-part 1. Overview of the IDAC Model," Reliability Engineering \& System Safety, vol. 92(8), pp. 997-1013, (2007).

[7] A. Mosleh and J. Y. H. Chang, "Model-Based Human Reliability Analysis: Prospects and Requirements," Reliability Engineering \& System Safety, vol. 83 (2), pp.241-253, (2004).

[8] A. Macwan and A. Mosleh, "Methodology for modeling Operator Errors of Commission in Probabilistic risk Assessment," Reliability Engineering \& System Safety, vol. 45(1-2), pp. 139157, (1994).

[9] A. Mosleh, J. A. Forester, R. L. Boring, S. M. Hendrickson, A. M. Whaley, S-H. Shen, D. L. Kelly, J. Y. H. Chang, V. N. Dang, J. H. Oxstrand and E. L. Lois, “A Model-Based Human Reliability Analysis Framework," Proceedings of the International Conference on Probabilistic Safety Assessment and Management (PSAM 10), Washington, USA, June 2010.

[10] A. Mosleh, S-H. Shen, D. L. Kelly, J. H. Oxstrand and K.M. Groth, "A Model-Based Human Reliability Analysis Methodology," Proceedings of the International Conference on Probabilistic Safety Assessment and Management (PSAM 11), Helsinki, Finland, June 2012.

[11] N. J. Ekanem, "A Model-Based Human Reliability Analysis Methodology (Phoenix Method)," Ph.D. dissertation, University of Maryland at College Park, 2013.

[12] N. J. Ekanem and A. Mosleh, "Phoenix -A Model-Based Human Reliability Analysis Methodology: Quantitative Analysis Procedure and Database," Proceedings of the International Conference on Probabilistic Safety Assessment and Management (PSAM 12), Hawaii, USA, June 2014.

[13] C. Smidts, S-H. Shen and A. Mosleh, "The IDA cognitive model for the analysis of nuclear power plant operator responses under accident conditions. Part 1: Problem solving and decision making model," Reliability Engineering and System Safety, vol. 55(1), pp. 51-71, (1997). 
[14] J. Oxstrand, D. L. Kelly, S-H. Shen, A. Mosleh and K. M. Groth, "A Model-Based Approach to HRA: Qualitative Analysis Methodology," Proceedings of the 11th International Conference on Probabilistic Safety Assessment and Management (PSAM 11), Helsinki, Finland, June 2012.

[15] N. J. Ekanem, A. Mosleh, S-H. Shen and J. Oxstrand, "Model-Based HRA Methodology: Procedures for Qualitative Analysis," Proceedings of the conference on Probabilistic Safety Assessment and Analysis (PSA 2013), South Carolina, USA, September 2013.

[16] Y. J. Chang, D. Bley, L. Criscione, B. Kirwan, A. Mosleh, T. Madary, ... \& A. Zoulis, "The SACADA database for human reliability and human performance," Reliability Engineering and System Safety, vol.125, pp. 117-133, (2014).

[17] Y. J. Chang and E. Lois, "Overview of the NRC's HRA Data Program and Current Activities," Proceedings of the International Conference on Probabilistic Safety Assessment and Management (PSAM 11), Helsinki, Finland, June 2012.

[18] S. M. Hendrickson, A. M. Whaley, R. L. Boring, J. Y. H. Chang, S-H. Shen, A. Mosleh, J. H. Oxstrand, J. F. Forester and D. L. Kelly, "A Mid-Layer Model for Human Reliability Analysis: Understanding the Cognitive Causes of Human Failure Events," Proceedings of the International Conference on Probabilistic Safety Assessment and Management (PSAM 10), Washington, USA, June 2010.

[19] F. V. Jensen and T. D. Nielsen, Bayesian Networks and Decision Graphs, New York: Springer, 2007.

[20] U. Kjaerulff and A. Madsen, Bayesian Networks and Influence Diagrams, New York: Springer, 2008.

[21] J. Pearl, Causality: models, reasoning, and inference, Cambridge University Press, 2000.

[22] K. M. Groth, "A data-informed model of performance shaping factors for use in human reliability analysis," Ph.D. dissertation, University of Maryland at College Park, 2009.

[23] K. M. Groth and A. Mosleh, "A data-informed PIF hierarchy for model-based human reliability analysis," Reliability Engineering and System Safety, vol.108, pp. 154-174, (2012).

[24] Y. J. Chang and A. Mosleh, "Cognitive modeling and dynamic probabilistic simulation of operating crew response to complex system accidents. Part 2 - IDAC performance influencing factors model," Reliability Engineering and System Safety, vol. 92(8), pp. 1014 - 1040, (2007).

[25] J. Williams, "A Data-Based Method for assessing and reducing Human Error to improve operational performance," Proceedings of the IEEE Conference on Human Factors in Power Plants, Monterey, California, 1988.

[26] A. Kolaczkowski, J. Forester, E. Lois and S. Cooper, "Good Practices for Implementing Human Reliability Analysis (HRA)," US Nuclear Regulatory Commission, Washington, DC, Tech. Rep. NUREG/CR-1792, 2005.

[27] B. Hallbert, R. Boring, D. Gertman, D. Dudenhoeffer, A. Whaley, J. Marble, J. Joe, and E. Lois, "Human events repository analysis (HERA) system overview," US Nuclear Regulatory Commission, Washington DC, Tech. Rep. NUREG/CR-6903, 2006.

[28] B. Hallbert, A. Whaley, R. Boring, P. McCabe, and Y. Chang, "Human event repository and analysis (HERA): The HERA coding manual and quality assurance," US Nuclear Regulatory Commission, Washington DC, Tech. Rep. NUREG/CR-6903, Volume 2, 2007.

[29] B. Kirwan, A guide to practical human reliability assessment, London: Taylor \& Francis, 1994.

[30] J. Cannon-Bowers and E. Salas, "Reflections on shared cognition," Journal of Organizational Behavior, vol. 22(2), pp. 195-202, (2001).

[31] B. Kim and R. Bishu, "On assessing operator response time in human reliability analysis (HRA) using a possibilistic fuzzy regression model," Reliability Engineering and System Safety, vol. 52(1), pp. 27-34, (1996).

[32] J. Julius, E. Jorgenson, G. Parry, and A. Mosleh, "Procedure for the analysis of errors of commission during non-power modes of nuclear power plant operation," Reliability Engineering and System Safety, vol. 53(2), pp. 139-154, (1996).

[33] J. Reason, Managing the risks of organizational accident, Ashgate Publishing Company, 1997.

[34] A. Tversky and D. Kahneman, "Judgment under uncertainty: Heuristics and biases," Science, vol. 185(4157), pp. 1124-1131, (1974). 
[35] K. Manktelow, Reasoning and thinking, Psychology Press Ltd., 1999.

[36] A. W. K. Gaillard, "Comparing the concepts of mental load and stress, " Ergonomics, vol. 36(9), pp. 991-1005, (1993).

[37] B. M. Huey and C. D. Wickens, "Workload transition: implications for individual and team performance," Washington DC, Commission on Behavioral and Social Sciences and Education, National Research Council, 1993.

[38] O. Svenson and A. Maule, Time pressure and stress in human judgment and decision making, Plenum Publishing Corporation, 1993. 